STONE CENTER ON SOCIO-ECONOMIC INEQUALITY

WORKING PAPER SERIES

No. 34

Occupational Dualism and Intergenerational Educational Mobility in the Rural Economy: Evidence from China and India

\author{
M. Shahe Emran \\ Francisco Ferreira \\ Yajing Jiang \\ Yan Sun
}

April 2021

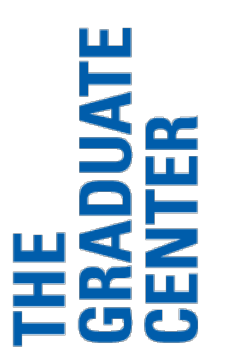




\title{
Occupational Dualism and Intergenerational Educational Mobility in the Rural Economy: Evidence from China and India
}

\author{
M. Shahe Emran ${ }^{1}$ \\ IPD, Columbia University \\ Francisco Ferreira \\ London School of Economics \\ Yajing Jiang \\ Charles River Associates \\ Yan Sun \\ World Bank
}

\begin{abstract}
This paper extends the Becker-Tomes model of intergenerational educational mobility to a rural economy characterized by farm-nonfarm occupational dualism and provides a comparative analysis of rural China and rural India. The model builds a micro-foundation for the widely used linear-in-levels estimating equation. Returns to education for parents and productivity of financial investment in children's education determine relative mobility, as measured by the slope, while the intercept depends, among other factors, on the degree of persistence in nonfarm occupations. Unlike many existing studies based on coresident samples, our estimates of intergenerational mobility do not suffer from truncation bias. The sons in rural India faced lower educational mobility compared with the sons in rural China in the 1970s to 1990s. To understand the role of genetic inheritance, Altonji et al. (2005) biprobit sensitivity analysis is combined with the evidence on intergenerational correlation in cognitive ability in economics and behavioral genetics literature. The observed persistence can be due solely to genetic correlations in China, but not in India. Father's nonfarm occupation was complementary to his education in determining a sons' schooling in India, but separable in China. There is evidence of emerging complementarity for the younger cohorts in rural China. Structural change in favor of the nonfarm sector contributed to educational inequality in rural India. Evidence from supplementary data on economic mechanisms suggests that the model provides plausible explanations for the contrasting roles of occupational dualism in intergenerational educational mobility in rural India and rural China.
\end{abstract}

Key Words: Educational Mobility, Rural Economy, Occupational Dualism, Farm-Nonfarm, Complementarity, Coresidency Bias, China, India

JEL Codes: O12, J62

\footnotetext{
${ }^{1}$ We are grateful to Forhad Shilpi for help with REDS data and insightful comments throughout this project, and to Yang Huang for help with the CFPS data. We would like to thank the participants in Equal Chances conference 2018, and LACEA conference 2019, and Matthew Lindquist, Guido Neidhofer, Reshad Ahsan, and Hanchen Jiang for helpful comments on an earlier draft and Rakesh Gupta Nichanametla Ramasubbaiah for excellent research assistance. An earlier version of the paper was titled "Intergenerational Educational Mobility in the Rural Economy: Evidence from China and India". This project was partially funded by World Bank RSB. The standard disclaimers apply. Email for correspondence: shahe.emran@gmail.com.
} 


\section{(1) Introduction}

Intergenerational persistence in economic status in developing countries has attracted the attention of policymakers and researchers in recent years, partly in response to growing evidence that economic liberalization increased income inequality in many countries, despite a significant reduction in poverty. ${ }^{2}$ In the absence of reliable income data over the life-cycle of parents and children, the focus of the recent literature on developing countries has been on intergenerational educational mobility. ${ }^{3}$ However, most of the recent studies are devoted to urban households, and intergenerational mobility in rural areas remains particularly under-researched, even though the bulk of the poor live in villages in developing countries. This paper provides a comparative analysis of intergenerational educational mobility in the rural areas of the two most populous countries in the world: China and India, with more than 1.5 billion people living in villages in $2000 / 2001 .^{4}$

While understanding the role of family background in the educational opportunities of 1.5 billion people is an important research agenda in itself, the policy differences between China and India make such a comparative study especially interesting. ${ }^{5}$ Perhaps, the most important difference in the 1970s to 1990s, the period during which the children in our empirical analysis went to school, was the restrictions on rural-urban migration in China because of the Hukou registration system. In contrast, there were no policy restrictions on rural-urban migration in India. Returns to education in farm vs. nonfarm occupations are also likely to be different in rural China because of policies such as the household responsibility system, rural industrialization (TVEs), and a lack of a well-functioning labor market in the 1970s to 1990s. Another important aspect in which rural India and rural China differed in this period is their schooling systems, with private schools playing a

\footnotetext{
${ }^{2}$ For recent contributions on China, see, among others, Fan et al. (2020), Park and Zou (2019), Sato and Li (2007), Emran and Sun (2015a)), on India see, among others, Azam and Bhatt (2015), Emran and Shilpi (2015), Asher et al. (2018), Ahsan et al. (2019), Emran et al. (2020). For cross-country analysis, see Behrman (2000), Hertz et al. (2007), and Neidhofer et al. (2018), among others. Among the few contributions on intergenerational persistence in health, see Bhalotra and Rawlings (2013).

${ }^{3}$ Educational mobility in this paper relates to schooling attainment. For a discussion on the broader concept of education in and outside the classroom as input to human capital production, see, for example, Behrman (2019).

${ }^{4}$ The rural population in India was 742.62 million in 2001 (72.16 percent of the total), according to the census of India 2001. In China, the rural population in 2000 was 807.39 million (64 percent of the total), according to the China Statistical Yearbook, 2011.

${ }^{5}$ China opened up its economy gradually from 1978, and the rural economy went through substantial policy changes starting with the household responsibility system that introduced market incentives at the margin. India liberalized its economy with a big bang in 1991, but the rural economy was relatively less affected as the initial trade protections were focused on the industrial sector as part of a planned industrialization strategy.
} 
much more prominent role in rural India. In our analysis, we pay close attention to the implications of these cross-country differences.

The standard model of intergenerational educational mobility where parent's education is the sole indicator of family background is not suitable for our analysis because it ignores occupational dualism in the rural economy. ${ }^{6}$ Children born into a nonfarm household may face different educational opportunities compared to the children born into a farming household even when the parents have similar educational background. At a given level of education, the parent's nonfarm occupation may affect investment in children's education through two major channels. First, higher income from nonfarm occupations may relax binding credit constraints on investment in schooling. ${ }^{7}$ Second, the probability of a child getting a nonfarm job may be higher when the parents themselves are employed in nonfarm occupations because of network, referral, and role model effects (Emran and Shilpi (2011)), and this would increase the optimal investment when returns to education are higher in nonfarm occupations.

There is substantial evidence that structural change in favor of non-farm occupations is an important source of increasing income inequality in villages of many developing countries. ${ }^{8}$ According to the estimates of Lanjouw et al. (2013) based on the data from Palanpur in the Indian state of Uttar Pradesh, the contribution of non-farm income to income inequality was only 4 percent in $1974 / 75$, which increased to 67 percent in $2008 / 09 .{ }^{9}$ The evidence on China also suggests that nonfarm income contributes to income inequality in rural areas (Rozelle ( 1994), Yang and An (2002)). Such a rise in inequality associated with the expansion of the nonfarm sector is of special concern when it reflects lower intergenerational mobility.

We develop a theoretical model in the tradition of Becker and Tomes (1986) that incorporates the role played by parental farm and nonfarm occupations in shaping children's educational opportunities, and yields the almost universally used linear-in-levels estimating equation. ${ }^{10}$ As emphasized by Mogstad (2017), in the absence of an explicit theoretical

\footnotetext{
${ }^{6}$ Although there is a long tradition in development economics following Lewis (1954) that emphasizes dualism as a central feature of underdevelopment, to the best of our knowledge, ours is the first paper to incorporate occupational dualism in an analysis of intergenerational educational mobility.

${ }^{7}$ However, in some countries, low-skilled nonfarm activities might be occupations of last resort, with low income, lower than the income of the farming households (Lanjouw and Lanjouw (2001)).

${ }^{8}$ For an excellent survey of the literature on rural nonfarm economy in developing countries, see Lanjouw and Lanjouw (2001). On rural China see Rozelle (1994), Yang and An (2002), and on rural India see Lnjouw et al. (2013).

${ }^{9}$ The Gini coefficient of income in Palanpur was 0.253 in $1974 / 75$ and 0.427 in 2008/09.

${ }^{10}$ The estimating equation used in the literature on intergenerational income mobility is log linear. In
} 
model, it is difficult to understand and interpret the economic content of the estimated intergenerational persistence. The theoretical analysis identifies a set of economic mechanisms determining the intercept and the slope of the intergenerational educational persistence equation. In particular, the household-level returns to education in the parental generation determine relative mobility as measured by the slope of the regression function (called intergenerational regression coefficient ( IGRC, for short) in the literature). The intercept which shows the expected schooling attainment of the children from the most disadvantaged family background (fathers with no schooling) is determined by intergenerational persistence in occupation, among other factors. ${ }^{11}$ A substantial literature shows that Hukou restrictions affected intergenerational persistence in nonfarm occupations in rural China (Wu and Treiman (2007)).

A credible empirical analysis of the role of occupational dualism in intergenerational educational persistence needs to address two major challenges highlighted in the recent literature: (i) truncation bias due to coresidency restrictions in surveys, and (ii) the role of genetic correlations in the observed intergenerational persistence. Most of the available household surveys, especially in developing countries, suffer from serious sample truncation as household membership is defined in terms of coresidency. ${ }^{12}$ Recent evidence indicates that the standard measures of relative mobility, such as IGRC, suffer from substantial downward bias in coresident samples (Emran, Greene, and Shilpi (2018)). Our empirical analysis focuses on the father-son linkage in education, and takes advantage of two exceptionally rich data sets: the rural sample from the China Family Panel Studies (2010) for China and the Rural Economic and Demographic Survey (1999) for India. Both of these surveys are unique in that they include all the children of the household head irrespective of their residency status at the time of the survey. ${ }^{13}$ This is especially important in a comparative study such as ours, because cross-country comparisons based on coresident samples can lead to wrong conclusions (see Emran, Greene, and Shilpi (2018) on Bangladesh and

contrast, all of the papers on intergenerational educational mobility we are aware of use a linear-in-levels estimating equation. This is partly motivated by the fact that, in many developing countries, 20-40 percent of fathers have zero schooling. However, we are not aware of any published work on developing countries that derives the estimating equation from a theoretical model.

${ }^{11}$ This deserves especial attention because the focus in much of the existing literature has been on the slope-based measures of mobility such as the intergenerational regression coefficient (IGRC) and intergenerational correlation (IGC).

${ }^{12}$ For example, widely used surveys such as LSMS and DHS collect information only on the coresident children.

${ }^{13}$ Although some surveys collect limited information on the non-resident parents of the household head and spouse, we are aware of only a few surveys that include all children of the household head. 
India).

A longstanding concern in the literature has been whether the observed correlations are primarily mechanical, driven largely by genetic transmissions from parents to children (see, for example, the discussion by Black and Devereux (2011)). We address this issue in two ways. First, we develop a simple but plausible approach to check whether the estimated intergenerational persistence could be due solely to genetic correlations. The approach combines the recent evidence on intergenerational correlation in cognitive ability from the behavioral genetics and economics literature with the Altonji, Elder, and Taber (2005) biprobit sensitivity analysis (henceforth called augmented AET (AAET) analysis). Second, the theoretical foundation for the empirical specification allows us to use economic mechanisms as a test for the importance of parental economic choices.

The substantive conclusions of this paper can be summarized as follows. Intergenerational educational mobility was substantially lower for sons in rural India compared to sons in rural China for the cohorts that went to school in the 1970s-1990s. The point estimates of intergenerational persistence are larger in nonfarm households in both countries. The difference between farm and nonfarm households is statistically significant in rural India, but not in rural China, and this conclusion applies to both the slope and the intercept of the intergenerational educational persistence regression. The evidence suggests that while parent's education and nonfarm occupation were complementary in determining a son's education in rural India, they were separable in rural China. ${ }^{14}$ The long-term variance in schooling was significantly higher for the sons born into nonfarm households in rural India, and structural change from agriculture to the nonfarm sector contributed to educational inequality. The evidence from the augmented AET sensitivity analysis shows that the observed persistence in rural India cannot be accounted for by genetic correlation alone, while the persistence in China can be explained away by an ability correlation of plausible magnitude. ${ }^{15}$ An important advantage of this approach is that the conclusions refer to the whole population of interest, rather than a subset as usually is the case with other standard approaches such as instrumental variables strategies.

\footnotetext{
${ }^{14}$ It is important to recognize that separability in rural China does not imply that nonfarm income did not play any role in rural income inequality; in fact, we cite a substantial literature to the contrary. The evidence in this paper suggests that intergenerational educational linkage is unlikely to be an important mechanism through which the nonfarm sector influenced the observed inequality in rural China in the 1980 s and 1990 s.

${ }^{15}$ This evidence on rural China is similar to the recent analysis on urban China based on a sample of monozygotic twins by Behrman et al. (2020). They find that the estimated impact of father's education can be explained fully by genetic correlations and unobserved family endowments.
} 
Under the null hypothesis that the observed persistence is due solely to genetics, the economic mechanisms identified in the theory are unlikely to provide a coherent explanation of the pattern of mobility across countries. We use household income data from Chinese Household Income Project (CHIP 2002, CHIP 1995) and National Sample Survey (NSS 1993) of India to explore the mechanisms behind the pattern of relative mobility (the IGRCs) across farm and nonfarm households. The evidence suggests an important role for the economic forces (returns to education and occupational persistence) in explaining the pattern of educational persistence across farm and nonfarm households, both in rural India and rural China. The theory also suggests that we should observe changes in the intergenerational educational persistence in rural China for the younger generation because of the effects of reform on the relevant mechanisms such as higher returns to education in nonfarm occupations. In contrast to the separability observed for the older cohorts, we indeed find evidence of emerging complementarity between father's education and nonfarm occupation in rural China for the educational attainment of the younger generation (18-28 years old in 2010).

The rest of the paper is organized as follows. Section 2 develops a model of intergenerational persistence with credit constraint that incorporates the salient features of farm vs. nonfarm households relevant for educational attainment. The next section describes the estimating equations derived from the theory and the empirical issues in understanding potential complementarity between parent's education and nonfarm occupation in determining children's schooling. Section 4 discusses the data and section 5 reports the main empirical estimates. The following section explores the evidence on the mechanisms identified by the theory underlying the observed pattern of slope (IGRC) and intercept estimates for the cohorts who went to school in the 1990s or earlier. Section 7 provides evidence on possible changes in the pattern of educational mobility in rural China for the younger generation (18-28 years old in 2010). The paper concludes with a summary of the main results from the theoretical and empirical analysis.

(2) A theory of Intergenerational Educational Persistence in a Dualistic Rural Economy

We develop an extension of the Becker-Tomes model with credit constraint (Becker and Tomes (1986)) to understand the role played by nonfarm occupations of parents in intergenerational educational mobility of children in a rural economy. The differences in expected returns to education in farm vs. nonfarm households are expected to play an 
important role. Expected returns to education in our context depends on two factors: the probability of getting a non-farm employment, and the difference between returns to education in farm vs. nonfarm occupations. The goal in this section is to derive an estimating equation that incorporates these differences in farm and nonfarm households.

\section{The Basic Set-up}

The economy consists of households with a father and a son. We couch the discussion in terms of father and son given that our empirical analysis focuses on the father-son linkages in schooling attainment. The father of child $i$ is described by a pair $\left(S_{i}^{P}, O_{i}^{p}\right)$ where $S_{i}^{p}$ is the education (years of schooling) and $O_{i}^{p} \in\{f, n\}$ with $f$ denoting farming occupation and $n$ denoting nonfarm occupation of the father. Given his education and occupation, the father's income is determined as follows: ${ }^{16}$

$$
Y_{i}^{p}=Y_{0}^{p j}+R^{p j} S_{i}^{p} ; j=f, n
$$

The income determination equation assumes that the fathers with zero years of schooling working in occupation $j$ earns $Y_{0}^{p j}>0$, and the returns to education in occupation $j$ is $R^{p j}$ for the parental generation. The assumption that $Y_{0}^{p j}>0$ is motivated by our empirical context where a substantial proportion fathers has zero years of schooling, but positive household income. It is important to underscore that the focus is on how a household's ability to invest in education changes with the education of the father. The "returns to education" relevant here thus relate to permanent household income, not an individual's labor market earnings in a given year which has been the focus of much of the literature on the Mincerian returns to education. ${ }^{17}$ In general, the intercepts are likely to be different, but whether $Y_{0}^{p n}$ is larger or smaller than $Y_{0}^{p f}$ will depend on the quality of the nonfarm activities at low education level $\left(S_{i}^{p}=0\right)$ which is likely to vary across countries. If low-end nonfarm activities have low-productivity, then it is possible that $Y_{0}^{p n}<Y_{0}^{p f}$.

The father allocates $Y_{i}^{p}$ to own consumption $C_{i}^{p}$ and investment in child's education $I_{i}$; thus the budget constraint is

$$
Y_{i}^{p} \geqq C_{i}^{p}+I_{i}
$$

The educational investment is made from a father's own income, as there is little or no

\footnotetext{
${ }^{16}$ This specification is similar to that in Solon (2004) and Becker et al. (2015).

${ }^{17}$ This point may be especially important in rural China during 1980s and early 1990s when the labor market was still not functioning very well, and the labor market earnings would be a poor measure of a household's economic status.
} 
financing available from the credit market for such investments in developing countries. The education production function for the child is as follows:

$$
S_{i}^{c}=F\left(I_{i}\right)=\theta_{0}+\theta_{1} \phi_{i}+\theta_{2} I_{i}
$$

The a priori sign restrictions are: $\theta_{0} \geq 0, \theta_{1}, \theta_{2}>0$. We would expect $\theta_{0}$ to be higher when government policies such as free primary schooling (including free books and midday meals etc) are in place so that a child can get a certain level of education, for example, primary schooling without any significant investment by the parents. $\phi_{i}$ is the ability of child $i$ and a higher ability produces more schooling, ceteris paribus. We normalize the ability measure such that $E\left(\phi_{i}\right)=0$.

The productivity of parental financial investment is represented by the parameter $\theta_{2}$ which captures, among other things, the quality of schools available (and affordable) to a family. For example, there is evidence that children have better learning outcomes in rural India when they attend private schools (Kingdon (2017)). The parents need to pay fees for private school while the public schools do not charge any fees, but the quality of schooling is, in general, low in the public schools. The productivity of financial investment is likely to be higher when the private education market is well-developed and parents can buy better quality by paying higher tuition and/or donations for admission. In contrast, when schooling is primarily provided by the government free of charge (including free books and midday meals) and the private market is thin or nonexistent, the role played by parent's investment in children's education is expected to be rather limited, making $\theta_{2}$ small. ${ }^{18}$ Note that the access to better quality schools does not depend on a parent's occupation in the formulation in equation (3) (i.e., $\theta$ is not indexed by $j$ ).

\section{Parent's Optimization}

The consumption sub-utility function of the parent is given by:

$$
U\left(C^{p}\right)=\alpha_{1} C^{p}-\alpha_{2}\left(C^{p}\right)^{2}
$$

Denote the expected income of a child $i$ with education $S_{i}^{c}$ at the time of the parental investment choice by $E\left(Y_{i}^{c} \mid S_{i}^{c}\right)$. The parent's optimization problem is (denoting the

\footnotetext{
${ }^{18}$ However, the "free schooling" offered by the governments may not be free, especially for the poor households, because of corruption when the enforcement system is not unbiased and impersonal. Emran, Islam, and Shilpi (forthcoming) show that, in Bangladesh, the poor parents are more likely to pay bribes for admission into "free" public schools.
} 
Lagrange multiplier on the budget constraint by $\lambda)$ :

$$
\operatorname{Max}_{C_{p}, I} V^{p}=U\left(C^{p}\right)+\sigma E\left(Y_{i}^{c} \mid S_{i}^{c}\right)+\lambda\left[Y_{i}^{p}-C_{i}^{p}-I_{i}\right]
$$

subject to (1) and (3). In this formulation, the parameter $\sigma$ is the degree of parental altruism. The expected income of the child $E\left(Y_{i}^{c} \mid S_{i}^{c}\right)$ depends on the probability of getting a nonfarm job, and is given as follows:

$$
E\left(Y_{i}^{c} \mid S_{i}^{c}\right)=\left[\pi_{i}^{n j} R^{c n}+\left(1-\pi_{i}^{n j}\right) R^{c f}\right] S_{i}^{c}
$$

where $\pi_{i}^{n j} \geq 0$ is the probability that child $i$ gets a nonfarm job when the father is employed in occupation $j=n, f$. To simplify notation, we write $\pi_{i}^{n}\left(O_{i}^{p}=j\right) \equiv \pi_{i}^{n j} ; j=n, f$. If there is intergenerational persistence in non-farm occupations then the probability that a child gets a nonfarm job is higher when the parent is also in the nonfarm occupations, i.e. $\pi_{i}^{n n}>\pi_{i}^{n f}$. This may reflect learning by doing at parent's workplace through informal apprenticeship, referral and network effects in the labor market, and role model effects (for a discussion, see Emran and Shilpi (2011)). Government policies also affect the strength of occupational persistence. As noted earlier, a major policy difference between rural India and rural China during our study period is the restrictions on rural-urban migration in China. These restrictions implied that many more children had to stay back in the rural areas in China compared to the counterfactual of no such restrictions (the India case). A substantial literature on occupational mobility in rural China shows that the Hukou restrictions reduced the persistence in non-farm occupations, as many children of the nonfarm parents had to take up farming activities because they could not migrate to the urban labor market. This implies that we should expect $\pi_{i}^{n n}($ India $)>\pi_{i}^{n n}($ China $)$.

The first order conditions for parent's optimization are:

$$
\begin{gathered}
\alpha_{1}-2 \alpha_{2} C^{p}-\lambda=0 \\
\sigma \theta_{2}\left\{\pi_{i}^{n j} R^{c n}+\left(1-\pi_{i}^{n j}\right) R^{c f}\right\}-\lambda=0
\end{gathered}
$$

The first order conditions and the budget constraint together yield the following solution for the optimal investment in a son's education:

$$
I_{i}^{*}=\chi_{0}^{j}+R^{p j} S_{i}^{p}
$$


where

$$
\chi_{0}^{j}=Y_{0}^{p j}+\frac{1}{2 \alpha_{2}}\left[\sigma \theta_{2}\left\{\pi_{i}^{n j} R^{c n}+\left(1-\pi_{i}^{n j}\right) R^{c f}\right\}-\alpha_{1}\right]
$$

\section{Intergenerational Persistence Equation}

Combining equations (3) and (8) above, we get the following relationship between the education of the father and that of a son, determined by the optimal investment decision:

$$
S_{i}^{c j *}=\psi_{0}^{j}+\psi_{1}^{j} S_{i}^{p}+\tilde{\varepsilon}_{i}
$$

where

$$
\begin{gathered}
\psi_{0 i}^{j}=\theta_{0}+\theta_{2} \chi_{0}^{j} \\
\psi_{1}^{j}=\theta_{2} R^{p j} \quad ; \tilde{\varepsilon}_{i}=\theta_{1} \phi_{i}
\end{gathered}
$$

Equation (10) is consistent with the almost universally used specification for intergenerational schooling persistence in the literature, but it allows for possible differences in educational opportunities across the farm and nonfarm households. Some examples of studies that use this linear-in-levels specification are: Neidhofer et al. (2018), Narayan et al. (2018) and Hertz et al. (2007) on cross-country analysis, Azam and Bhatt (2015) and Emran and Shilpi (2015) on India, and Emran and Sun (2015a) on China. However, we are not aware of any studies on intergenerational educational mobility in developing countries that derive the estimating equation from a theoretical model.

It is standard to assume homothetic functional forms in the analysis of intergenerational income mobility, as the estimating equation is log-linear (see, for example, Solon $(1999,2004))$. The reliance on the linear in levels (years of schooling) specification in the literature on intergenerational educational persistence partly reflects the fact that a substantial proportion of fathers have no schooling. This is especially relevant in the rural areas of developing countries such as India where about 40 percent of fathers have no schooling (estimate based on REDS 1999 data). The estimating equation (10) is also consistent with the common assumption in the literature that the omitted ability is captured in the error term of the intergenerational persistence regression, and can lead to ability bias in the OLS estimates of the parameters. ${ }^{19}$

An important implication of equation (10) is that both the slope and the intercept of

\footnotetext{
${ }^{19}$ Although most of the existing studies on intergenerational mobility adopt this additively separable specification for the impact of ability, there is little evidence on the validity of this assumption. In a recent paper, Ahsan et al. (2020) use measures of ability based on Raven's test and two memory tests in Indonesia and find evidence in favor of this assumption.
} 
the persistence equation capture the differences in educational opportunities faced by the children in farm vs. nonfarm households, although the existing literature focuses largely on the slope (IGRC).$^{20}$ An interpretation of the intercept term in our context is that it provides an estimate of the expected education of the children from the subset of households where the fathers have zero schooling. Thus, the intercept estimate may be especially important in developing countries where a significant proportion of the households have parents with zero schooling in the data. In the empirical analysis, we thus pay close attention to the estimated intercepts across farm and nonfarm households in addition to the standard relative mobility measures based on slopes.

Equally important, equations (10) and (11) help improve our understanding of the economic mechanisms behind the observed pattern of mobility. For example, consider the factors that determine the intercepts across farm and nonfarm households. The intercept is, ceteris paribus, higher (lower) for the nonfarm children when the income of the parents with zero schooling is higher (lower) in the nonfarm occupations. These nonfarm occupations are, however, likely to be unskilled as they do not require any schooling. In some countries, the low-skilled nonfarm occupations may yield very low income, lower than the income of the farmers (Lanjouw and Lanjouw (2001), World Bank (2011)), making the intercept for the nonfarm households smaller. Another important implication, noted before, is that intergenerational persistence in occupational choices is likely to affect the relative magnitudes of the intercept terms. When $\hat{\pi}_{i}^{n n}>\hat{\pi}_{i}^{n f}$, it is more likely to have $\hat{\psi}_{0}^{n}>\hat{\psi}_{0}^{f}$, ceteris paribus, assuming that $R^{c n}>R^{c f}$. Conversely, if $\hat{\pi}_{i}^{n n}>\hat{\pi}_{i}^{n f}$ but $R^{c n}<R^{c f}$, then it is more likely to have $\hat{\psi}_{0}^{n}<\hat{\psi}_{0}^{f}$, ceteris paribus. This implies that the evidence on intergenerational occupational persistence (farm vs. nonfarm) accumulated independently in a sub-strand of the literature is necessary to understand the pattern of intergenerational educational mobility in a rural economy. As emphasized by Emran and Shilpi (2019), the interactions between occupational and educational mobility are not considered in the existing literature on developing countries; there are two sub-strands of the literature that grew independently: one focusing solely on education and the other focusing solely on occupation.

The relative magnitudes of the slope parameters (IGRC) across farm and nonfarm

\footnotetext{
${ }^{20}$ For example, none of the 13 studies on educational mobility in developing countries summarized in Emran, Greene, and Shilpi (2018) report estimates of intercepts. Some of the more recent works report measures of absolute mobility that combines both the slope and the intercept effects (following Chetty et al. (2014)), but do not report the intercept estimates separately.
} 
households depend on the household returns to education in the parental generation $\left(R^{p j}\right)$ according to equation (11). Thus, $R^{p n}>R^{p f}$ generates complementarity between parent's education and occupation in determining children's schooling. ${ }^{21}$ This provides testable implications to check the importance of economic forces in the observed differences in relative mobility across farm and nonfarm households in China vs. India. ${ }^{22}$

\section{(3) Empirical Approach}

Equation (10) above suggests the following estimating equation for the combined farm and nonfarm sample which we take as a benchmark:

$$
S_{i}^{c}=\psi_{0}+\psi_{1} S_{i}^{p}+\varepsilon_{i}
$$

where $\varepsilon_{i}=\tilde{\epsilon}_{i}+\eta_{i}=\theta_{1} \phi_{i}+\eta_{i}$, and $\eta_{i}$ captures exogenous idiosyncratic shocks to children's schooling. We normalize so that $E\left(\eta_{i}\right)=0$. The corresponding estimating equation allowing for different intercepts and slopes for the farm and nonfarm households is:

$$
S_{i}^{c}=\psi_{0}^{f}+\psi_{1}^{f} S_{i}^{p}+\lambda_{0} D_{i}^{n p}+\lambda_{1}\left(S_{i}^{p} * D_{i}^{n p}\right)+\Phi X_{i}+\varepsilon_{i}
$$

where $D_{i}^{n p}$ is a dummy variable that takes on the value of 1 when the father of child $i$ is employed in nonfarm occupations, and zero otherwise. In this formulation, the measure of relative mobility is IGRC: $\psi_{1}^{f}$ for the farm households and $\psi_{1}^{f}+\lambda_{1}$ for the nonfarm households; we denote $\psi_{1}^{f}+\lambda_{1} \equiv \psi_{1}^{n}$. Similarly, the intercepts are given by $\psi_{0}^{f}$ (farm) and $\psi_{0}^{n} \equiv \psi_{0}^{f}+\lambda_{0}$ (nonfarm). $X_{i}$ is a set of controls used in the regressions. Following the seminal contribution of Solon (1992), it is standard in the literature on intergenerational income mobility to include quadratic age controls for both the parents and the children. This helps reduce the biases that arise from life-cycle effects in estimating permanent income. ${ }^{23}$ The life-cycle bias is not likely to be a concern in our application, as we chose the age cut-off to ensure that most of the children completed schooling by the time the survey was done.

\footnotetext{
${ }^{21}$ The analysis shows that different roles are played by the parental returns to education and the expected returns to education in children's generation, a point not adequately recognized in the current literature. It is important to appreciate that the children's expected returns to education at the time of the investment decision do not affect the slope (IGRC), their effects are mediated only through the intercept of the persistence regression.

${ }^{22}$ Returns to education are identified as a major factor in changes in intergenerational income persistence (see Becker and Tomes (1979, 1986), Solon (1999, 2004)).

${ }^{23}$ When data on many years spanning the appropriate phases of life-cycle are available, the age controls are not necessary. Some recent contributions do not include any age controls, as it may wipe out the inter-cohort differences in income mobility.
} 
Our main estimates thus do not include any age controls; but, as a robustness check, we report estimates including age controls.

It is important to appreciate that a comparison of farming and nonfarming households based solely on the most widely used measure of mobility, i.e., IGRC $\left(\psi_{1}^{f}\right.$ and $\left.\psi_{1}^{n}\right)$, may be misleading. The caveat that IGRC or other measures of relative mobility such as intergenerational correlation (IGC) may be misleading in comparing mobility across groups has been emphasized by Hertz (2005), Mazumder (2014) and Bhattacharya and Majumder (2011) in their analysis of racial (black-white) differences in intergenerational income mobility in United States of America. But it has not been adequately appreciated in the literature on intergenerational educational mobility, both in economics and sociology. ${ }^{24}$ This is especially so in developing countries, as is evident from the fact that most of the available studies on China and India we are aware of focus exclusively on relative mobility measures such as IGRC, IGC (intergenerational correlation) and IRC (intergenerational rank correlation).

To see the pitfalls in relying on IGRC alone in our context, it is instructive to consider the case where $\psi_{1}^{n}>\psi_{1}^{f}$ so that intergenerational persistence is higher in nonfarm households. However, whether this higher persistence leads to convergence or divergence in schooling attainment of children born into farm and nonfarm households depends on the relative magnitudes of the intercepts. When the intercepts are $\psi_{0}^{n}>\psi_{0}^{f}$, the expected schooling is higher for children born into nonfarm households across the distribution of parental schooling, and the gap between the two groups widens as parental education increases (please see figure 1). On the other hand, we can have two sub-cases when the intercepts are: $\psi_{0}^{n}<\psi_{0}^{f}$ (please see figure 2). If the IGRC for the nonfarm group is high enough, the children born to lower educated nonfarm households are disadvantaged compared to the children of low-educated farmer parents, but at the higher end of parental education distribution they are relatively advantaged (see nonfarm(a) line in figure 2). When the difference between IGRC estimates is small enough, the farmer's children are better off in educational attainment over the entire distribution, and only in this special case, the conclusion based on IGRC that nonfarm children face lower relative mobility is consistent with the idea that they are at a disadvantage in educational attainment (please see the nonfarm(b) line in figure 2).

\section{Rank-Based Measures of Intergenerational Mobility}

While most of the existing studies on intergenerational educational mobility in de-

\footnotetext{
${ }^{24}$ See the discussion on this point by Torche (2015) in the context of Sociological literature on mobility.
} 
veloping countries rely on years of schooling as the indicator of educational attainment, following the influential contribution of Chetty et al. (2014), the recent literature is increasingly adopting the rank-based measures where the indicator of educational status is the percentile rank in the relevant distribution. A growing literature suggests that the rankbased measures of mobility are significantly more robust to data limitations compared to the measures based on years of schooling. ${ }^{25}$

Denote $r_{i}^{c}$ as the percentile rank of child $i$ in the over-all (including both farm and nonfarm) schooling distribution of children, and $r_{i}^{p}$ the percentile rank of the father of $i$ in the over-all schooling distribution in fathers generation. For the rank-based estimates, the estimating equations are as follows:

$$
\begin{gathered}
r_{i}^{c}=\delta_{0}+\delta_{1} r_{i}^{p}+\xi_{i} \forall i \\
r_{i}^{c}=\delta_{0}^{f}+\delta_{1}^{f} r_{i}^{p}+\lambda_{2} D_{i}^{n p}+\lambda_{3}\left(r_{i}^{p} * D_{i}^{n p}\right)+\xi_{i}
\end{gathered}
$$

The slope parameters of regression equations (14)- (15) represent intergenerational rank correlation (IRC, for short) which is a measure of relative mobility similar to IGRC. The IRCs are given by $\delta_{1}^{f}$ (farm) and $\delta_{1}^{n} \equiv \delta_{1}^{f}+\lambda_{3}$ (nonfarm). Similar relations hold for the intercepts. However, there are important differences between IGRC and IRC as measures of mobility. While the IGRC estimates reflect the effects of changing marginal distributions across generations, the IRC provides a measure of fundamental dependence between the schooling of father and son largely unaffected by the changes in the marginal distributions. However, the interpretation of rank correlation (IRC) in education (a discrete variable) is somewhat different than that of income (a continuous random variable). With continuous variables, Spearman rank correlation is a copula, completely unaffected by the changes in the marginal distributions. In contrast, rank correlation in discrete variables such as education is not completely immune to changes in the marginal distributions (see the discussion in Neslehova (2007)).

\footnotetext{
${ }^{25}$ Nybom and Stuhler (2017) find that rank-based measures are much less affected by attenuation bias due to measurement error in income, and Emran and Shilpi (2018) show that the truncation bias due to coresidency restrictions in surveys is significantly lower in rank-based measures compared to the most widely used measure IGRC in the context of educational persistence. For a more in-depth discussion on these issues, see Emran and Shilpi (2019).
} 


\section{Interaction between Parent's Education and Occupation: Complementary,} Substitutes or Separable?

An important advantage of the empirical models discussed above is that they provide a straight-forward way to test the nature of interaction between parent's occupation and education in determining intergenerational persistence in schooling. Consider, for example, the estimating equation (13) above; from the theoretical analysis in section (2), it is easy to derive the conditions under which parental education and non-farm occupation can be complementary, i.e., $\lambda_{1}>0$ implying $\left(\psi_{1}^{n}>\psi_{1}^{f}\right)$, substitutes, i.e., $\lambda_{1}<0$ implying $\left(\psi_{1}^{n}<\psi_{1}^{f}\right)$, or separable, i.e., $\lambda_{1}=0$ implying $\left(\psi_{1}^{n}=\psi_{1}^{f}\right)$. The prevailing view among many observers is that nonfarm occupation and education are likely to be complementary in determining children's education, leading to cumulative forces of inequality in educational attainment and income in villages in developing countries (see, for example, Rama et al. (2015)). Yet, to the best of our knowledge, there is no evidence in the literature on the existence and the nature of the interaction between parent's education and occupation in determining children's educational attainment. Also, without a formal model, the economic mechanisms behind the hypothesized complementarity cannot be assessed. According to the theoretical model above, such complementarity requires that returns to education for the parents is higher in non-farm occupations, i.e., $R^{p n}>R^{p f}{ }^{26}$ This is one of the predictions that we take to the data as a test of the importance of economic mechanisms underlying the observed pattern of intergenerational educational persistence.

\section{(4) Data}

For our main empirical analysis, we use two exceptionally rich surveys that collected data on children irrespective of their residency status at the time of the survey. The data for rural India come from the Rural Economic and Demographic Survey (REDS) carried out by the National Council for Applied Economic Research, and the source of the data for rural China is the China Family Panel Studies (CFPS) implemented by the Institute of Social Science Survey unit of Peking University. ${ }^{27}$

\footnotetext{
${ }^{26}$ If private school locations are motivated by higher income associated with nonfarm activities, then school quality may also play a role in generating complementarity. In this case, the productivity of parental investment $\theta_{2}$ will be correlated with occupation, i.e., $\theta_{2}^{n}>\theta_{2}^{f}$.

${ }^{27}$ One might wonder why we chose not to use the IHDS 2012 round survey for India which would provide a survey year close to the survey year of CFPS in China. The CFPS and REDS are the most comparable in that they provide a random sample of parents with information on all their children irrespective of the residency status of a child at the time of the survey. The IHDS, in contrast, contains a random sample of children with information on their parents irrespective of their residency status at the time of the survey.
} 
This is an important advantage for the empirical analysis, as most of the evidence on intergenerational educational mobility in India and China currently available are based on data that suffer from truncation due to coresidency restrictions used to define household membership. Emran, Greene, and Shilpi (2018) summarize 13 studies on intergenerational educational mobility in developing countries, only two of which use data not affected by coresidency bias. ${ }^{28}$ While Emran, Greene and Shilpi (2018) provide evidence of substantial downward bias (average 18 percent) in the IGRC estimate from the coresident sample in rural India, we are not aware of any similar estimate for rural China. In online appendix A, we provide evidence on the extent of coresidency bias in rural China in a widely used household survey: the Chinese Household Income Project (CHIP). In particular, we compare the estimates from the CFPS (without any sample truncation) with those from the CHIP 2002 for the overlapping age cohorts. The evidence shows that the IGRC estimate from the CHIP 2002 is 25 percent smaller because of truncation of the sample arising from coresidency restrictions (see Table A.2 in the online appendix). A comparison of CHIP 2002 with the CFPS is also of independent interest, because CHIP 1995 and 2002 have been used by many researchers to study intergenerational mobility in China. ${ }^{29}$ For a more complete discussion, please see online appendix A.

We use the 1999 round of the REDS and the first round of the CFPS in 2010. From the REDS data, we obtain the relevant information for our analysis on all father-son pairs irrespective of residency status at the time of the survey. For the CFPS data, we restrict to rural communities subsample, given our focus on intergenerational mobility in rural areas, and use the family roster to obtain a complete list of father-son pairs that includes all sons of the household head irrespective of their residency status at the time of the survey.

The main samples for our analysis consist of children aged 18 - 54 in the 1999 REDS survey, and 29 - 65 in the 2010 CFPS survey. This ensures that we focus on the same age cohorts of children who went to school mostly during the 1980s and 1990s. It is important to recognize that such an analysis for the overlapping age cohorts is meaningful for education, as most of the children under focus (29-65 years old in 2010) in China have completed their schooling by 1999, even though the information was gathered later in 2010 . The

\footnotetext{
${ }^{28}$ The exceptions are Fan et al. (2019) and Azam and Bhatt (2015).

${ }^{29}$ Two of the authors of this paper, M. Shahe Emran and Yan Sun, used CHIP 2002 data to analyze the effects of farm and nonfarm occupations on intergenerational educational mobility in rural China (see Emran and Sun (2015b)). We decided not to publish that paper because of the worry about the biases due to sample truncation arising from coresidency. This paper replaces Emran and Sun (2015b) and the conclusions on rural China here supersede those in Emran and Sun (2015b).
} 
observations with fathers aged over 100 years or missing, or sons aged over 65 years are excluded from the samples used in the empirical analysis.

In each data set, we observe the education level and an indicator of whether the main occupation is agriculture or nonfarm activity for both the father and the son. Our main analysis of educational mobility is based on years of schooling as the measure of educational attainment. Father's schooling is used as the indicator of parental education to avoid complications from many missing observations on mother's schooling. In our data sets, the maximum of parental education coincides with the education level of the father in most of the cases. We define the parental occupation dummy $D_{i}^{n p}=0$ when the father of child $i$ reports agriculture as the main occupation (corresponding to $O_{i}^{p}=f$ in the theoretical model), $D_{i}^{n p}=1$ otherwise. This means that the households who are primarily engaged in farming with some nonagricultural sources of income are classified as agricultural occupation.

Online appendix Table A.1 shows the descriptive statistics of our main data samples from the REDS and the CFPS. In the REDS sample, we have 6887 observations, and the children's age is 29 years on average in the survey year 1999. Fathers are 60 on average. About half of the children's main occupation is agriculture, while $60 \%$ of the fathers also reported agriculture as their main occupation. The children attain significantly higher levels of education than the fathers, when comparing their average years of schooling (6.26 vs. 4.13.)

In CFPS sample, a similar pattern is observed. We have 3,305 father-son pairs, and children's age is about 40 years in the survey year, 2010 (29 years in 1999, same as that for India in 1999 REDS data). Fathers are aged 68 years on average in 2010. About half of the fathers work in the agricultural sector. Children receive 6.31 years of schooling on average, significantly higher than their fathers (less than 3.81 years).

While our main empirical analysis is based on the CFPS 2010 and REDS 1999, we take advantage of a number of additional data sets for exploring the economic mechanisms identified by the theoretical analysis. To understand how the relation between father's education and household income varies by farm and nonfarm occupation in rural China we utilize the data from the Chinese Household Income Project (CHIP) 1995 and 2002. To estimate the relation between father's education and household income in rural India, we use the data on household total expenditure from the National Sample Survey 1993. 


\section{(5) Empirical Results}

\section{(5.1) Evidence on Relative Mobility and Test of Complementarity}

Table 1 reports the estimates of relative mobility using two measures: intergenerational regression coefficient (IGRC) and intergenerational rank correlation (IRC). In addition to the separate estimates for the farm and nonfarm households, we report the estimates from the combined farm and nonfarm sample as a benchmark.

The point estimates of IGRC show that, both in rural India and rural China, intergenerational persistence in schooling is higher for the sons born into nonfarm households, but the estimates for farm and nonfarm households are similar in magnitude in China. A son of a father with 1 year more schooling in India is expected to gain 0.49 year of schooling if the father is a farmer, while the expected gain increases to 0.56 year of schooling when the father is employed in nonfarm occupation (column 2 of Table 1). The corresponding estimates for rural China are 0.31 year (farm) and 0.32 year (nonfarm) of additional schooling for the sons born to a father with 1 year of more schooling (column 1 of Table 1). Another important conclusion from the evidence in Table 1 is that all of the IGRC estimates in rural China are smaller compared to the corresponding estimates in rural India, providing strong evidence that the sons in rural China who went to school in the 1980s and 1990s enjoyed substantially more relative mobility in schooling. The conclusions above remain valid when we include age controls in the specifications (see Table A.3 in the online appendix ). ${ }^{30}$

The estimates of intergenerational rank correlation (IRC) reported in columns 3 and 4 of Table 1 also tell a similar story: the point estimates of the effect of father's schooling rank on the son's schooling rank are higher for the nonfarm households, both in China and India. Again, the effect of parental education does not vary substantially between farm and nonfarm household in rural China, but there is substantial difference in rural India. The magnitudes of the IRCs are consistently smaller in rural China compared to those in India, reinforcing the conclusion from the IGRC estimates that the sons in rural India faced lower educational mobility. These conclusions from the IRC estimates remain intact when we include age controls in the specification (see Table A.4 in the online appendix).

The contrasting evidence in China vs. India suggests that father's education and nonfarm occupation are likely to be complementary in India, but separable in China. We formally test the null hypothesis of separability $H_{0}: \psi_{1}^{f}=\psi_{1}^{n}$. The results are reported

\footnotetext{
${ }^{30}$ Since life-cycle bias is not likely to be a major issue in our context, our preferred estimates are from the specification without age controls.
} 
in the lower panel of Table 1, with standard errors clustered at the primary sampling unit (village in REDS data, and county in CFPS data). The evidence from both IGRC and IRC estimates shows that, in rural China, the null hypothesis of separability cannot be rejected at the 10 percent significance level; the $\mathrm{F}$ statistic for IGRC estimates is 0.014 with a P-value of 0.90, and the corresponding numbers for IRC are 0.13 (F statistic) and 0.72 (P-value). In contrast, in rural India, the null hypothesis of separability is rejected at the 10 percent level for IGRC $(\mathrm{F}=3.80, \mathrm{P}$-value=0.052), and at the 5 percent level for IRC $(\mathrm{F}=6.42, \mathrm{P}$-value=0.012). Since the estimated effect of parental schooling is larger in the nonfarm households in rural India, the evidence suggests complementarity between nonfarm occupation and father's education in determining a son's schooling.

\section{Relative Mobility and Long-Term Variance in Schooling}

When interpreted as a dynastic model of the evolution of schooling across generations, a higher IGRC implies a higher long-term variance in schooling. ${ }^{31}$ To see this, note that for the IGRC equation (12), we can write the long-term variance of education as:

$$
\sigma_{s}^{2}=\frac{1}{\left(1-\psi_{1}^{2}\right)} \sigma_{\varepsilon}^{2}
$$

where $\sigma_{s}^{2}$ is the long-term variance of education and $\sigma_{\varepsilon}^{2}$ is the long-term variance of the error term capturing all other factors unrelated to father's schooling such as market luck, and macro and trade shocks. $\frac{1}{\left(1-\psi_{1}^{2}\right)}$ is called the 'family background multiplier' by Emran and Shilpi (2019), which amplifies the impact of the shocks to education. Using equation (16) and the estimates of $\psi_{1}^{f}$ and $\psi_{1}^{n}$ reported in Table 1, we have the following estimates for sons in farm and nonfarm households in rural India:

$$
\begin{aligned}
& \sigma_{s, I f}^{2}=1.31 \sigma_{\varepsilon}^{2} \quad(\text { farm }) \\
& \left.\sigma_{s, I n}^{2}=1.45 \sigma_{\varepsilon}^{2} \quad \text { (nonfarm }\right)
\end{aligned}
$$

The subscripts $I$ and $s$ denote India and schooling, respectively, and as before, $n=$ nonfarm and $f=$ farm. The long-term variance of education of sons in the farming sample is 31 percent higher than the variance due to idiosyncratic factors alone (i.e., $\sigma_{\varepsilon}^{2}$ ), and is 45 percent higher in the nonfarm sample. Thus the contribution of family factors to the long-term variance is 14 percentage points higher in the nonfarm households.

\footnotetext{
${ }^{31}$ For a discussion on the dynastic interpretation of the model and the implications for long-term variance, see Acemoglu and Autor (undated).
} 
The long-term variances in schooling for the farm and nonfarm households in China are:

$$
\begin{aligned}
& \sigma_{s, c f}^{2}=1.107 \sigma_{\varepsilon}^{2} \quad(\text { farm }) \\
& \sigma_{s, c n}^{2}=1.111 \sigma_{\varepsilon}^{2} \quad(\text { nonfarm })
\end{aligned}
$$

The multiplier effect of family background is much smaller in the case of China; the longterm variance in schooling is only about 10 percent higher than the variance of idiosyncratic shocks, and the estimates are virtually identical across the farm and nonfarm samples.

\section{(5.2) Intercepts and Steady States}

As noted earlier, measures of relative mobility give us an incomplete, and sometimes misleading, picture of intergenerational mobility across groups such as farm and nonfarm households. A simple but important reason is that different groups may be converging to different steady states due to different intercepts in the intergenerational persistence equations. Perhaps more importantly, the theory in section (2) suggests that factors such as persistence in occupation choices, and expected returns to investment in schooling for children work through the intercept, leaving relative mobility as measured by IGRC and IRC largely unaffected.

The estimated intercepts of equations (12)-(13) and (14)-(15) above are reported in Table 2. The point estimates show that the intercept of the IGRC equation in India is significantly higher for the farm households (p-value 0.013). The evidence for the intercept of the IRC equation is similar ( $p$-value 0.006). When considered along with the evidence that the slope estimates (IGRC and IRC) are smaller for the farm households in India, the evidence implies a set of interesting conclusions. First, whether the sons born to fathers in farm or nonfarm occupation enjoy educational advantage depends on the level of their fathers' education with a switching threshold of 9-10 years of schooling. Please see figure 3. An interpretation of the evidence is that the national public examination administered at 10th grade (known as Matriculation examination, or all India Secondary School Examination (SSC)) represents a bifurcation point. The children of non-farm fathers with Matriculation or more schooling are expected to achieve better schooling attainment when compared to the children of farmer fathers with similar educational credential, but the children of nonfarm fathers with lower education (and probably unskilled nonfarm jobs) are likely to be worse-off when compared to the children of low educated farmer fathers (who likely own land). Second, the steady state level of education is not substantially different across farm and nonfarm households: 10.81 years of schooling (farm) and 11.20 years of 
schooling (nonfarm). This reflects the fact that the sons born into nonfarm households gain more from the higher schooling of a father, although they start from a lower intercept.

The picture for rural China is different (please see figure 4). The evidence in Table 2 shows that there is no statistically significant difference across the farm and nonfarm households in the intercepts of the intergenerational persistence regressions (p-values are 0.279 (IGRC intercept) and 0.43 (IRC intercept)). When combined with the evidence on IGRC and IRC in Table 1, this implies that the schooling attainment of the sons in rural China converges to virtually the same steady state (8.53 years of schooling) irrespective of whether the father is a farmer or is engaged in a nonfarm occupation. ${ }^{32}$

\section{(5.3) Structural Change and Cross-Sectional Schooling Inequality}

To understand the implications of the higher variance in the nonfarm households in India for the cross-sectional variance in rural schooling, it is important to consider the structure of the rural economy (i.e., proportion of fathers employed in the nonfarm sector) and both the within group and between groups variances. Denote the proportion of nonfarm households by $\omega$, then we can write the long-term variance as:

$$
\operatorname{Var}(S)=\omega \sigma_{s, n}^{2}+(1-\omega) \sigma_{s, f}^{2}+\omega(1-\omega)\left(\mu_{f}-\mu_{n}\right)^{2}
$$

where $\mu_{n}$ and $\mu_{f}$ are the long-term means (the steady state) of father's education in farm and nonfarm households, respectively. The effects of a marginal increase in the proportion of nonfarm sector is given by:

$$
\frac{d \operatorname{Var}(S)}{d \omega}=\left(\sigma_{s, n}^{2}-\sigma_{s, f}^{2}\right)+(1-2 \omega)\left(\mu_{f}-\mu_{n}\right)^{2}
$$

As discussed in sections (5.1) and (5.2) above, there are no significant differences in the long-term means or long-term variances across the farm and nonfarm households in rural China. This implies that both terms in equation (18) are zero, indicating that structural change in favor of the non-farm sector during the decades of 1970s-1990s is unlikely to contribute to the cross-sectional variance of schooling. As noted earlier, this, however, does not imply that the nonfarm sector did not play any role in the increasing income inequality in rural China during this period, only that the nonfarm sector's effect is not mediated through intergenerational educational persistence.

\footnotetext{
${ }^{32}$ The estimate of the steady state is based on the combined farm and nonfarm sample. Although they are not statistically different, the point estimates differ numerically across farm and nonfarm subsamples.
} 
In India, the evidence in section (5.1) shows that the long-term variance is substantially higher in the nonfarm households because of a large family background multiplier. The estimates of the long-term (steady state) means also show a higher mean for the nonfarm households. When we plug in the estimates from sections (5.1) and (5.2) for rural India in equation (18) above, we get (using $\omega=0.40$ from the summary statistics table in online appendix):

$$
\left.\frac{d \operatorname{Var}(S)}{d \omega}\right|_{\text {India }}=0.078+0.13 \sigma_{\varepsilon}^{2}>0
$$

Thus, the evidence suggests that structural change in favor of the nonfarm sector contributed to higher cross-sectional variance in rural India during our study period.

(6) Economic Mechanisms: Towards an Explanation of the Differences between Rural China and Rural India

A major concern in the literature has been whether the observed pattern of intergenerational linkages is primarily driven by omitted variables bias due to unobserved genetic correlations between parents and children. An obvious approach to this question is to try to correct the estimates for possible positive bias due to genetic correlations in cognitive ability. We develop a simple but plausible approach by taking advantage of the recent evidence on intergenerational correlation in cognitive ability from economics and behavioral genetics. There is substantial evidence that intergenerational correlation in cognitive ability (denoted as $\rho$ ) falls in a narrow interval, $\rho \in[0.20,0.40]$; see, for example, Black et al. (2009), Bjorklund et al. (2010) on economic literature, and Plomin and Spinath (2004) on behavioral genetics literature. We use this information in a biprobit sensitivity analysis as developed by Altonji et al. (2005) to check if the estimates of intergenerational persistence in schooling remain positive and statistically significant for plausible values of intergenerational correlation in ability. We call this approach augmented AET (AAET) sensitivity analysis, and it requires binary indicators of educational attainment instead of years of schooling. We use a dummy for higher than primary schooling for fathers. For sons in rural China a dummy for higher than 9 years of schooling (higher middle school), and for sons in rural India, a dummy for more than 10 years of schooling (called SSC or matriculation) are used. The details of this approach are provided in online appendix B, and the estimates are reported in Table 3.

The evidence from the AAET sensitivity analysis suggests that, the estimated intergenerational schooling persistence in India is very strong, and the estimates remain statistically 
significant and numerically substantial even when we impose $\rho=0.40$ in the biprobit model. In contrast, the estimates turn negative in the case of rural China when $\rho=0.30$, suggesting that the observed positive effect of father's education could be explained away by ability correlation between parents and children. ${ }^{33}$ This evidence strengthens substantially the conclusions that educational mobility was much lower in India in the 1970s-1990s, and that economic forces are likely to be important in explaining the differences between India and China. The advantage of this approach is that it is easily implementable, and thus could be used fruitfully by other researchers. However, it is also important to appreciate the limitations of such an a-theoretical approach. For example, the evidence that the persistence in rural China could be explained by genetic correlations alone does not necessarily imply that economic forces were not at play. The theoretical analysis in section (2) provides us a way to explore the question by focusing on the economic mechanisms behind the pattern of the slope and intercept estimates across farm and nonfarm households. We turn to this exercise next.

Under the null hypothesis that genetic transmission is the main force at work, we should not expect the economic mechanisms identified in the model to offer a consistent explanation of the observed pattern of intergenerational persistence across India and China. If economic forces are important, the theory provides us with testable implications even in the case of rural China; the equality of the slopes (IGRCs) across the farm and nonfarm households in this case implies equality of the returns to education for the farm and nonfarm parents.

\section{(6.1) Differences in the IGRCs}

The estimates of IGRC in Table 1 imply the following (denoting an estimate by a hat):

$$
\begin{array}{cc}
\text { (China) } & \hat{\psi}_{1}^{f}=\hat{\psi}_{1}^{n} \Rightarrow \theta_{2} \hat{R}^{p f}=\theta_{2} \hat{R}^{p n} \\
\text { (India) } & \hat{\psi}_{1}^{f}<\hat{\psi}_{1}^{n} \Rightarrow \theta_{2} \hat{R}^{p f}<\theta_{2} \hat{R}^{p n}
\end{array}
$$

The theoretical analysis thus highlights the importance of household-level returns to schooling in the father's generation $\left(R^{p j}\right)$ across occupations for understanding the pattern of relative mobility. We have $\hat{\psi}_{1}^{f}-\hat{\psi}_{1}^{n}=\theta_{2}\left(\hat{R}^{p f}-\hat{R}^{p n}\right)$, and the effects of a widening gap in returns to education for household income between farm and nonfarm households would be low if $\theta_{2}$, the productivity of financial investment in children's education, is low. We would expect $\theta_{2}$ to be low when the private market for education is not well-developed in a

\footnotetext{
${ }^{33}$ These conclusions remain robust when we define the schooling cut-off to be the same in the two countries, and also when age controls are included in the specification. The details are available from the authors.
} 
country. ${ }^{34}$ Since the expansion of private schooling has been much larger in India compared to that in China during the study period, the value of $\theta_{2}$ is likely to be higher in India.

It is important to recognize that the "returns to education" for the parents (i.e., $R^{p j}$ ) differ from most of the available estimates of returns to education for three reasons. First, we are interested in the total income of all household members rather than the individual income (i.e., not only father's income). Second, the focus of the existing literature has been on labor market returns, while our analysis requires both labor and non-labor income. Third, father's education in our analysis is not only a measure of human capital, but a summary statistic for a family's socio-economic status and captures the effects of other correlated factors, for example, mother's education due to assortative matching in the marriage market. ${ }^{35}$ Thus, we need a measure of permanent household income.

The Chinese Household Income Project (CHIP) provides us with high quality household income data for rural households for multiple years (5 years in CHIP 2002, and 3 years in CHIP 1995). ${ }^{36}$ Unlike China, the data on household income in rural India are, however, more limited; we are not aware of any household survey data set that has good quality income information for consecutive multiple years, similar to the CHIP data on China. We thus take household expenditure reported in the National Sample Survey as our measure of household permanent income.

Table 4 (panel A) provides estimates of household-level returns to education, $R^{p n}$ and $R^{p f}$, in rural China and tests the null hypothesis that $R^{p n}=R^{p f}$ using data from two rounds (1995 and 2002) of the Chinese Household Income Project (CHIP) survey. The standard errors are clustered at the primary sampling unit (county). The estimates based on the 5-year average income of a household in CHIP 2002 data in the last two columns of Table 4 show that the null hypothesis cannot be rejected with a P-value equal to $0.58 .{ }^{37}$ The evidence from the 1995 data (three year average income) also delivers a similar conclusion: the null hypothesis cannot be rejected with a P-value of $0.33 .^{38}$ The conclusion that returns

\footnotetext{
${ }^{34}$ To see this clearly, consider the polar case where schooling is provided only by the government free of charge and there is no private schools (or private tutoring). In this case, the scope for parental financial investment to improve a child's educational attainment is effectively nonexistent, making $\theta_{2} \approx 0$.

${ }^{35}$ The available estimates on Mincerian labor market returns to education at the individual level in China show low returns in the early years after the reform, but there is evidence of increasing returns in the later years, as one would expect with the deepening of the labor market. The evidence also suggests higher labor market returns in nonfarm occupations (DeBrauw and Rozelle (2008)).

${ }^{36}$ Note that the estimates of the effects of father's education on household permanent income using CHIP data do not suffer from truncation bias, unlike the estimates of intergenerational persistence; whether some of the children were nonresident at the time of the survey is not relevant for this analysis.

${ }^{37}$ The 5 year income data cover from 1998 to 2002 in the CHIP 2002.

${ }^{38}$ The 3 years income data in CHIP 1995 cover 1991, 1993, and 1995.
} 
to education measured in permanent household income do not differ significantly across farm and nonfarm households in rural China during the study period is robust to inclusion of number of children in the household as a control (see online appendix Table A.5). The evidence on household-level returns to education when put together with the evidence on complementarity discussed earlier in Table 1 provide a theoretically consistent explanation: a lack of difference in returns to education across farm and non-farm occupations leads to separability between father's education and nonfarm occupation in determining son's schooling in rural China.

Also, the magnitude of $\theta_{2}$ is likely to be low in rural China during the relevant period (the children who went to school during 1970s-1990s) which would reduce the impact of any emerging advantage in favor of nonfarm households in returns to education. Recall that $\theta_{2}$ is the efficiency of parental investment, determined primarily by the supply side of the education market such as availability of high-quality private schools. In China, the availability of private schools was limited; in 1996, only 4 percent of the schools in China were private (Kwong (1996)). Most of the private schools in rural areas in the 1990s were primary schools with limited facilities and equipment, and they catered to children from

the low-income households. At the secondary level, the private schools primarily met the demand by the students who were unsuccessful in the admission test given after grade 9 to screen for the senior secondary public schools (Lin (1999)). This implies that, in contrast to many other countries, any quality advantage in education in rural China is associated with better quality public schools. While local financing and various types of fees increasingly played a role in public schools after the fiscal decentralization, it is unlikely to create a significant impact on the magnitude of $\theta_{2}$ for the following reason: the share of private expenditure remained small compared to the public expenditure during the 1980s and 1990s; for example, tuition and other fees paid by the parents amount to only 4.42 percent of total educational expenditure in 1991 and 10.72 percent in 1995 (see Table 7.2 in Hannum et al. (2008)).

$\underline{\text { Rural India }}$

For the estimates of IGRCs across farm and nonfarm households in India to be consistent with the extended Becker-Tomes model of section (2), the returns to schooling in nonfarm households need to be higher than that in the farming households in the parental generation. Table 4 (panel B) reports the estimates of household-level returns to education in rural India using household expenditure data from the NSS 1993 survey (the employment and 
unemployment round). The returns to education are, in fact, higher in nonfarm occupations and the difference is significant at the 5 percent level $(\mathrm{P}$-value $=0.02)$. The conclusion that returns to education at the household level are higher for the nonfarm activities is robust; for example, the null hypothesis of equality is rejected with a $\mathrm{P}$-value $=0.002$ when we control for number of children in the household (see the online appendix Table A.5).

The available evidence also suggests that the magnitude of $\theta_{2}$ is likely to be much higher in rural India when compared to that in rural China. A higher value of $\theta_{2}$ would act as a multiplier for higher returns to schooling in nonfarm activities for the parents, and amplify the difference between farm and nonfarm slopes (IGRCs). This can lead to the complementarity we found earlier in Table 1 above. In India, private schools have historically been more important than in rural China, and they have become more important over time, especially after the liberalization in 1991. Muralidharan and Kremer (2008) report that, in 2003, 28 percent of rural households had access to fee-charging private schools. They also provide evidence that private schools are more likely to be established in places where public school quality is low, and the students in private schools perform better academically. ${ }^{39}$ Thus, the relative quality of private and public schools in rural India is opposite to that in rural China. This suggests that the higher income (and better educated) households can take advantage of the high-quality private schools making $\theta_{2}$ higher. Since the private schools are more likely to locate in villages where the public school quality is low, the differential effects of school quality are likely to be strong in rural India, as the better educated nonfarm parents with high income send children to private schools, and the other children (including the children of low-educated and low-skilled nonfarm parents) go to low quality public schools.

\section{(6.2) Differences in the Intercepts}

According to the theory, the estimated intercepts in Table 2 discussed above imply the following relations (using a hat to denote an estimate):

$$
\begin{array}{ll}
(\text { China }) & \hat{\psi}_{0}^{f} \approx \hat{\psi}_{0}^{n} \Longrightarrow Y_{0}^{p f}+\frac{1}{2 \alpha_{2}}\left[\sigma \theta_{2} E\left(R I^{c f}\right)-\alpha_{1}\right] \approx Y_{0}^{p n}+\frac{1}{2 \alpha_{2}}\left[\sigma \theta_{2} E\left(R I^{c n}\right)-\alpha_{1}\right] \\
(\text { India }) & \hat{\psi}_{0}^{f}>\hat{\psi}_{0}^{n} \Longrightarrow Y_{0}^{p f}+\frac{1}{2 \alpha_{2}}\left[\sigma \theta_{2} E\left(R I^{c f}\right)-\alpha_{1}\right]>Y_{0}^{p n}+\frac{1}{2 \alpha_{2}}\left[\sigma \theta_{2} E\left(R I^{c n}\right)-\alpha_{1}\right]
\end{array}
$$

\footnotetext{
${ }^{39}$ Private schools have more teachers with college degree and teacher absenteeism is less of a problem compared to the public schools. Azam et al. (2016) find that the students in private secondary schools in rural Rajasthan scored about 1.3 standard deviation (SD) higher than their counterparts in the public schools in a comprehensive standardized math test.
} 
where $E\left(R I^{c j}\right)=\left\{\pi_{i}^{n j} R^{c n}+\left(1-\pi_{i}^{n j}\right) R^{c f}\right\}$ is the expected return to financial investment in son's education when the father is employed in occupation $j=n, f$.

\section{$\underline{\text { Rural China }}$}

The following observations are important for understanding the role played by occupational persistence in educational mobility in rural China. First, when $\pi_{i}^{n n} \simeq \pi_{i}^{n f}$, we have $E\left(R I^{c n}\right) \simeq E\left(R I^{c f}\right)$, irrespective of whether $R^{c n}>R^{c f}$ or $R^{c n} \leq R^{c f}$. Since expected returns to education for the children do not vary significantly across farm and nonfarm households in this case, we would expect parental investment in education and thus educational mobility to be similar also. The second observation is that when there is low or no intergenerational persistence in nonfarm (or farm) occupations, we have $\pi_{i}^{n n} \simeq \pi_{i}^{n f}$.

A substantial body of independent evidence, in fact, suggests that, for the relevant cohorts, there was no significant intergenerational persistence in nonfarm occupation choices $\left(\pi_{i}^{n n} \simeq \pi_{i}^{n f}\right)$ in rural China. Wu and Treiman (2007) use the 1996 national probability sample of Chinese men and show that there is high degree of mobility into agriculture; the sons of nonfarm parents also face a substantial probability of becoming a farmer. They identify the geographic restrictions on mobility of rural people because of the Hukou registration system as the primary factor behind this weak intergenerational persistence in nonfarm occupations. ${ }^{40}$ Using CHIP 2002 data, Emran and Sun (2015) report evidence supporting $\mathrm{Wu}$ and Treiman (2007) finding.

The evidence that $E\left(R I^{c n}\right)=E\left(R I^{c f}\right)$, along with equation (19), above implies that a sufficient condition for the equality of the intercepts of the intergenerational persistence equations is that $Y_{0}^{p n}=Y_{0}^{p f}$, i.e., the intercepts of the returns to education function in parent's generation are the same across farm and nonfarm households. We would expect $Y_{0}^{p n}=Y_{0}^{p f}$ when the fathers with zero schooling have similar income (permanent income) and face similar credit constraint, irrespective of their occupation.

The estimates in panel A of Table 4 show that the null hypothesis $Y_{0}^{p n}=Y_{0}^{p f}$ cannot be rejected at the 10 percent level with a p-value of 0.78 for the CHIP 2002 data on five-year average income. The evidence from 1995 data is also similar (p-value is 0.81). Again, these conclusions from CHIP 2002 and CHIP 1995 remain intact when we include number of

\footnotetext{
${ }^{40}$ The link between restrictions on geographic mobility of rural people and a lack of intergenerational occupational persistence (farm/nonfarm) is, however, not unique to China, similar evidence is available on Vietnam where the Ho Khau registration system has been in place since 1964; see the evidence and the analysis in Emran and Shilpi (2011). This enhances the credibility of Wu and Treiman (2007) analysis that the Hukou restrictions played an important role in the low occupational persistence in rural China.
} 
children in the household as a control (please see online appendix Table A.5).

The evidence above is also consistent with other available studies on the nonfarm sector and rural industries (TVEs) in rural China. The income gap between the farm and nonfarm households was mitigated in the early years of reform by two factors: the household responsibility reform increased farmer's income, and, in many cases, people employed on the farm were paid wages similar to the wages paid to workers in the township village enterprises (TVEs), the growing TVE sector in effect subsidizing the agricultural employment (Peng, 1998). This also reflects in part the lingering effects of policies during the cultural revolution that were successful in eliminating any significant differences between the peasants and non-peasants in rural China (Hannum et al. (2008)).

\section{$\underline{\text { Rural India }}$}

In contrast to China, there were no restrictions on rural-urban migration in India during the study period. A substantial body of independent evidence on occupational mobility in rural India suggests strong intergenerational persistence in farm/nonfarm occupations (Reddy (2015), Motiram and Singh (2012), Azam (2015), Hnatvoska et al. (2013)). Hnatvoska et al. (2013) show that there is strong persistence in rural occupations both in 1983 and 2004-2005; the son of a farmer is highly likely to be a farmer himself. Using the IHDS (2005) survey, Motiram and Singh (2012) also provide similar evidence. The fact that there was significant persistence in farm/nonfarm occupations implies that the expected returns to investing in children's education are likely to differ across farm and nonfarm households. But whether the intercept in the nonfarm households would be higher or lower depends partly on the expected relative returns to education in the children's generation, i.e., whether $R^{c n}>R^{c f}$ or $R^{c n}<R^{c f}$. It is, however, much more difficult to estimate expected returns to education for children. One can argue that parent's expectation would depend on their information set, a salient element in which is his own returns to education. In other words, the evidence of higher returns to education in nonfarm in the parental generation suggests that the parents would expect similarly higher returns for children in nonfarm occupations. Note that even when $R^{c n}>R^{c f}$, the intercept for the nonfarm households can be smaller as we find in the empirical analysis above (Table 2), if the households with zero (or very low) parental schooling have sufficiently lower income in nonfarm occupations, i.e., $Y_{0}^{p n}<Y_{0}^{p f}$.

The estimates of $Y_{0}^{p n}$ and $Y_{0}^{p f}$, i.e., the intercepts of the income equation for parents, using data from NSS 1993 round (employment and unemployment round), are reported 
in panel B of Table 4. The estimated intercept is larger for the farm households and the difference is statistically significant at the 10 percent level (standard errors clustered at the PSU level). The evidence in favor of a larger intercept in the farm households is stronger when we add controls to the regression; for example, the difference is significant at the 1 percent level when number of children is added to the specification (see online appendix Table A.5). This conclusion is also supported by other available evidence on India; for example, the All India Debt and Investment Survey 1991 (NSS 48th round) shows that the assets of farming households ("cultivators") are higher than those of the nonfarming households (see P. ii, NSSO report No. 491, 1998).

The evidence in panel $\mathrm{B}$ of Table 4 also accords well with a substantial body of related evidence available on the nonfarm activities in India. Note that it is likely to have $Y_{0}^{p n}<Y_{0}^{p f}$ if the low-end nonfarm occupations are primarily low productivity residual activities and provide the last resort for the poorest households. Lanjouw and Murgai (2011) use three rounds of NSS data (1983, 1993/94, and 2004/2005) and show that nonfarm employment is positively associated with rural poverty in India, consistent with the observation that nonfarm employment involves primarily low productivity economic activities (see also World Bank (2011)).

This evidence on the intercepts of the income equation provides an explanation for the higher intercept for farm households in the intergenerational mobility equation as discussed earlier.

(7) Evolution of Mobility: Evidence on the Younger Generation in Rural China

The rural economy and educational policies in China went through significant changes in recent decades. The changes include gradual relaxation of Hukou restrictions, increasing returns to education as the labor market matured, accelerated structural change in favor of the nonfarm sector, and a more prominent role for private educational expenditure after the fiscal decentralization (for an excellent discussion, see Fan et al. (2020)). ${ }^{41}$ There is credible evidence that the economic changes have adversely affected intergenerational mobility of the younger generation in China. Fan et al. (2020) find that intergenerational income persistence has increased over time; they report an IGE estimate of 0.390 for the

\footnotetext{
${ }^{41}$ The share of tuition and miscellaneous fees in educational expenditure rose from 4.42 percent in 1991 to 18.59 percent in 2004 (Hannum et al. (2008). The spread of better quality public schools to the rural areas has accelerated. All these changes would increase the magnitude of $\theta_{2}$ in the extended Becker-Tomes model for the younger generation.
} 
1970-1980 birth cohorts, which increased to 0.442 for the 1981-1988 birth cohorts. The extended Becker-Tomes model suggests that the pattern of educational persistence across farm and nonfarm households should also change for the younger generation because of the changes in the economic mechanisms.

To check if the pattern of educational mobility across farm and nonfarm households has changed in the younger generation, we estimate the intergenerational educational mobility equation for 18-28 years age cohorts who were excluded from our main estimation sample. ${ }^{42}$ The estimates are reported in Table 5, with the upper panel containing the results for years of schooling, and the lower for rank-based estimates. There is, in fact, evidence of emerging divergence between farm and nonfarm households in relative mobility as measured by IGRC and IRC. For example, the IGRC estimate for the farm households has declined a bit from 0.31 (main sample) to 0.27 (younger sample), while the IGRC estimate has increased for the nonfarm households from 0.316 (older) to 0.34 (younger). Similarly, the IRC estimate for farm households declined from 0.331 (main sample) to 0.304 (younger sample), and it has increased from 0.337 (main sample) to 0.373 (younger sample) for the nonfarm households. The difference between farm and nonfarm households is significant at the 10 percent level in the case of IRC estimates $(\mathrm{P}$-value $=0.097)$. While the difference in IGRC estimates is not significant at the 10 percent level, the p-value in the younger sample is much smaller: 0.107 (younger sample) vs. 0.90 (main sample), providing evidence in favor of emerging complementarity between father's education and nonfarm occupation.

\section{(8) Conclusions}

This paper develops a model of intergenerational educational persistence in a rural economy taking into account the role of parental farm vs. nonfarm occupations, and derives a theoretically-grounded estimating equation which we take to the data from rural India and rural China. We use two unique data sets that include the required information for all the children of the household head irrespective of their residency status at the time of the survey; thus eliminating the truncation bias common in the existing studies based on the standard surveys that use coresidency criteria to define household membership.

The empirical analysis delivers the following conclusions for the sons who went to school in the 1990s or earlier: (i) the intergenerational educational mobility in rural China was significantly higher compared to that in rural India, (ii) the farm/nonfarm occupations

\footnotetext{
${ }^{42}$ Our main estimation sample consists of 29-65 age cohorts in 2010 to ensure that the sample of children in China refers to the same age groups as in the data for India.
} 
did not play any significant role in the intergenerational schooling linkage in rural China, and this is true for both the intercept and the slope of the intergenerational persistence regressions, (iii) both the slopes and intercepts were significantly different across farm and nonfarm households in rural India. The estimates suggest that father's education and nonfarm occupation were complementary in determining son's schooling in rural India, but separable in rural China. Structural change in favor of the nonfarm sector contributed to higher educational inequality in rural India during the study period, in part due to the complementarity. In contrast, such structural change was not an important factor in schooling inequality in rural China. Evidence from an approach that combines the biprobit sensitivity analysis of Altonji et al. (2005) with recent evidence on intergenerational correlation in cognitive ability suggests that the observed educational persistence in rural India is unlikely to be due solely to mechanical transmission of ability across generations, while the persistence in rural China could be explained by genetic correlations alone.

We analyze whether the economic forces identified in the extended Becker-Tomes model provide a coherent explanation of the observed pattern of educational mobility across countries (rural China vs. rural India) and over time (older vs. younger cohorts in rural China). A lack of intergenerational persistence in nonfarm occupations in rural China because of the Hukou restrictions seems to have played an important role in making the intercepts similar in rural China, but strong intergenerational occupational persistence in rural India resulted in significant differences between farm and nonfarm households. In rural India, the observed complementarity can be explained by higher returns to education in nonfarm occupations in the parental generation. The separability between father's education and occupation in rural China was driven by the absence of any significant differences in the household-level returns to education across farm and nonfarm occupations. However, because of economic forces unleashed by the policy reform in China, the returns to education in nonfarm occupations for parents have increased and Hukou restrictions have been relaxed progressively. According to the theory, this should tighten the link between father's education and son's schooling in the nonfarm sector. Indeed, we find evidence that the separability between father's education and occupation broke down for the 18-28 years old sons, implying that structural change in favor of the nonfarm sector is increasingly contributing to educational inequality in rural China. 


\section{References}

Acemoglu, D, and D. Autor (undated), Lectures in Labor Economics, Book Manuscript, MIT.

Ahsan, Nazmul, M. Shahe Emran, and Forhad Shilpi (2020), "The Rural-Urban Divide and Intergenerational Educational Mobility in a Developing Country: Theory and Evidence from Indonesia", Working Paper, World Bank.

Ahsan, Reshad, Arpita Chatterjee, and M. Shahe Emran (2019), "Are Markets Substitutes for Better Educated Parents? Evidence from Intergenerational Educational Mobility in Rural India", Paper presented at the Royal Economic Society Annual Conference, 2019, University of Warwick.

Altonji, Joseph G., Todd E. Elder, and Christopher R. Taber (2005). "Selection on Observed and Unobserved Variables: Assessing the Effectiveness of Catholic Schools." Journal of Political Economy 113, no. 1, pp. 151-84. doi:10.1086/426036.

Asher, S, P. Novosad, and C. Rafkin (2018), "Intergenerational Mobility in India: Estimates from New Methods and Administrative Data", Working Paper, Dartmouth College.

Azam, Mehtabul, and Vipul Bhatt. (2015). "Like Father, Like Son? Intergenerational Educational Mobility in India. Demography 52(6):192959.

Azam, Mehtabul \& Geeta Kingdon \& Kin Bing Wu, (2016). " Impact of private secondary schooling on cognitive skills: evidence from India," Education Economics, Taylor \& Francis Journals, vol. 24(5), pages 465-480, September.

Bardhan, Pranab. (2014). "The State of Indian Economic Statistics: Data Quantity and Quality Issues. Unpublished.

Becker, Gary S \& Tomes, Nigel, 1986. "Human Capital and the Rise and Fall of Families," Journal of Labor Economics, University of Chicago Press, vol. 4(3), pages 1-39, July.

Behrman, J \& Yuan Hu \& Junsen Zhang, (2020). "The Causal Effects of Parents' Schooling on Children's Schooling in Urban China," PIER Working Paper Archive 20-005, Penn Institute for Economic Research, Department of Economics, University of Pennsylvania.

Behrman Jere, (2019). "Human capital and social mobility in low- and middle-income countries," WIDER Working Paper Series wp-2019-85, World Institute for Development Economic Research (UNU-WIDER).

Behrman, J., E. Hannum, M. Wang, and J. Liu (2008): Education in the Reform Era, in 
Brandt and T. Rawski Ed: China's Great Economic Transformation, Cambridge university Press.

Behrman, Jere, A. Gaviria and M. Szekely (2001), "Intergenerational Mobility in Latin America, Economía, Vol. 2 (1): 144.

Bhalotra, Sonia, and Samantha Rawlings. (2013). "Gradients of Intergenerational Transmission of Health in Developing Countries." Review of Economics and Statistics 95(2):66072.

Bjorklund A and K. Salvanes. (2011). "Education and Family Background: Mechanisms and Policies," Handbook in the Economics of Education vol 3, E A Hanushek, S Machin and L Woessmann (es.), pp. 201-247.

Black, S. E. and P. Devereux (2011). "Recent Developments in Intergenerational Mobility", Handbook of Labor Economics.

Black, S. E, Paul J. Devereux, and Kjell G. Salvanes (2009), "Like father, like son? A note on the intergenerational transmission of IQ scores", Economics Letters, Volume 105, Issue 1, 2009, Pages 138-140.

Chetty, Raj, Nathaniel Hendren, Patrick Kline, and Emmanuel Saez. (2014). "Where Is the Land of Opportunity? The Geography of Intergenerational Mobility in the United States. The Quarterly Journal of Economics 129(4):1553123.

de Brauw, Alan, and Scott Rozelle, (2008), "Reconciling the Returns to Education in Rural China," Review of Development Economics 12(1): 57-71.

Emran, M. Shahe, and Forhad Shilpi. (2011). "Intergenerational Occupational Mobility in Rural Economy: Evidence from Nepal and Vietnam." Journal of Human Resources 46(2):42758.

Emran, M. Shahe, and Forhad Shilpi. (2015). "Gender, Geography and Generations: Intergenerational Educational Mobility in Post-Reform India." World Development $72: 36280$.

Emran, M Shahe, \& William Greene, \& Forhad Shilpi, (2018). "When Measure Matters: Coresidency, Truncation Bias, and Intergenerational Mobility in Developing Countries," Journal of Human Resources, University of Wisconsin Press, vol. 53(3), pages 589-607.

Emran, M. Shahe, and Sun Yan. (2015a). "Magical Transition? Intergenerational Educational and Occupational Mobility in Rural China: 1988-2002." World Bank Policy Research, Working Paper 7316.

Emran, M. Shahe \& Sun,Yan (2015b). "Are the children of uneducated farmers doubly 
disadvantaged? Farm, nonfarm and intergenerational educational mobility in rural China," Policy Research Working Paper Series 7459.

Emran, M. Shahe, \& Shilpi, Forhad J., (2018). "Estimating intergenerational mobility with incomplete data: Coresidency and truncation bias in rank-based relative and absolute mobility measures," Policy Research Working Paper Series 8414, The World Bank.

Emran, M. Shahe \& Shilpi Forhad, (2019). "Economic approach to intergenerational mobility: Measures, methods, and challenges in developing countries," WIDER Working Paper Series wp-2019-98, World Institute for Development Economic Research (UNUWIDER).

Emran, M. Shahe \& Jiang, Hanchen \& Shilpi, Forhad, (2020). "Gender Bias and Intergenerational Educational Mobility: Theory and Evidence from China and India," GLO Discussion Paper Series 497, Global Labor Organization (GLO).

Emran. M Shahe, \& Asadul, Islam \& Forhad, Shilpi, (forthcoming). "Distributional Effects of Corruption When Enforcement is Biased: Theory and Evidence from Bribery in Schools in Bangladesh," forthcoming in Economica.

Fan, Yi, Junjian Yi and Junsen Zhang, (2020) "Rising Intergenerational Income Persistence in China", forthcoming in American Economic Journal: Economic Policy.

Hnatkovska, V \& Amartya Lahiri \& Sourabh B. Paul, (2013). "Breaking the Caste Barrier: Intergenerational Mobility in India," Journal of Human Resources, University of Wisconsin Press, vol. 48(2), pages 435-473.

Hertz, Tom, Tamara Jayasundera, Patrizio Piraino, Sibel Selcuk, Nicole Smith, and Alina Veraschagina. 2007. "The Inheritance of Educational Inequality: International Comparisons and Fifty-Year Trends." The B.E. Journal of Economic Analysis and Policy: Advances 7(2).

Knight, John, Terry Sicular, and Yue Ximing. (2013). Educational Inequality in China: the Intergenerational Dimension. in Rising Inequality in China: Challenge to the Harmonious Society, eds. Li Shi, Luo Chuliang, and Terry Sicular, ch.4. Cambridge and New York: Cambridge University Press.

Lanjouw, P, \& Rinku Murgai, \& Nicholas Stern, (2013). "Nonfarm diversification, poverty, economic mobility, and income inequality: a case study in village India," Agricultural Economics, vol. 44(4-5), pages 461-473, July.

Lanjouw, P, \& Rinku Murgai, (2009). "Poverty decline, agricultural wages, and nonfarm employment in rural India: 1983-2004," Agricultural Economics, vol. 40(2), pages 243-263, 
March.

Lanjouw, Jean O. \& Lanjouw, Peter, (2001). "The rural non-farm sector: issues and evidence from developing countries," Agricultural Economics, Blackwell, vol. 26(1), pages 1-23, October.

Lefgren, Lars, \& Matthew J. Lindquist, \& David Sims, (2012). "Rich Dad, Smart Dad: Decomposing the Intergenerational Transmission of Income," Journal of Political Economy, University of Chicago Press, vol. 120(2), pages 268-303.

Li, Hongbin, Prashant Loyalka, Scott Rozelle, and Binzhen Wu. (2017). "Human Capital and China's Future Growth." Journal of Economic Perspectives, 31 (1): 25-48.

Lin, Jing (1999), Social Transformation and Private Education in China, Praeger, CT, USA.

Mazumder, Bhashkar, (2014). "BlackWhite Differences in Intergenerational Economic Mobility in the U.S," Economic Perspectives, Federal Reserve Bank of Chicago, issue Q I, pages $1-18$.

Mogstad, M (2017). "The Human Capital Approach to Intergenerational Mobility," Journal of Political Economy, University of Chicago Press, vol. 125(6), pages 1862-1868.

Motiram, Sripad \& Singh, Ashish, (2012). "How Close Does the Apple Fall to the Tree? Some Evidence on Intergenerational Occupational Mobility from India," WIDER Working Paper Series 101, World Institute for Development Economic Research (UNU-WIDER).

Muralidharan, K and M. Kremer (2008), Public-Private Schools in Rural India, in Chakrabarty, R and Peterson, P ed. School Choice International: Exploring Public-Private Partnerships, MIT Press.

Narayan, A, \& Roy Van der Weide, \& Alexandru Cojocaru, \& Christoph Lakner, \& Silvia Redaelli, \& Daniel Gerszon Mahler, \& Rakesh Gupta N. Ramasubbaiah, \& Stefan Thewissen, (2018). Fair Progress? Economic Mobility across Generations Around the World," World Bank Publications, The World Bank, number 28428, March.

Neidhöfer, G, Joaquín Serrano, Leonardo Gasparini (2018), "Educational inequality and intergenerational mobility in Latin America: A new database", Journal of Development Economics, Volume 134, 2018, Pages 329-349.

Neslehova, J (2007), "On rank correlation measures for non-continuous random variables", Journal of Multivariate Analysis, vol. 98, issue 3, pp. 544-567.

Park, Albert, and Xianqiang Zou (2019). Intergenerational Mobility Pathways: Evidence from a Long Panel from Rural China, Working paper, HKUST. 
Peng, Yusheng (1998), "Agriculture, Rural Industries, and Peasant Income in China", Development and Society, June 1998.

Rama, M, \& Tara Béteille, \& Yue Li, \& Pradeep K. Mitra, \& John Lincoln Newman, (2015). "Addressing Inequality in South Asia," World Bank Publications, The World Bank, number 20395, March.

Reddy, A. Bheemeshwar, (2015), "Changes in Intergenerational Occupational Mobility in India: Evidence from National Sample Surveys, 19832012", World Development, 76, issue C, p. 329-343.

Rozelle, Scott. 1994. "Rural Industrialization and Increasing Inequality: Emerging Patterns in Chinas Reforming Economy." Journal of Comparative Economics, Vol. 19, Iss. 3, pp. 362-391

Sato, Hiroshi and Shi Li. 2007. Class origin, family culture, and intergenerational correlation of education in rural China. IZA Discussion Paper series No. 2642.

Solon, Gary. 1992. "Intergenerational Income Mobility in the United States. American Economic Review 82(3):393408.

Solon, Gary. 1999. "Intergenerational Mobility in the Labor Market. In Handbook of Labor Economics, Vol. 3, ed. O. Ashenfelter and D. Card, Elsevier: Amsterdam, North Holland.

Torche, Florencia. (2015). "Intergenerational Mobility and Equality of Opportunity, European Journal of Sociology 56(3): 343371.

Yang, Dennis Tao and An, Mark Yuying, 2002. "Human capital, entrepreneurship, and farm household earnings, Journal of Development Economics, Elsevier, vol. 68(1), pages 65-88, June.

Wu, Xiaogang, and Donald J. Treiman. (2007), "Inequality and Equality under Chinese Socialism: The Hukou System and Intergenerational Occupational Mobility." American Journal of Sociology 113, no. 2 (2007): 415-45. 


\section{FIGURE 1}

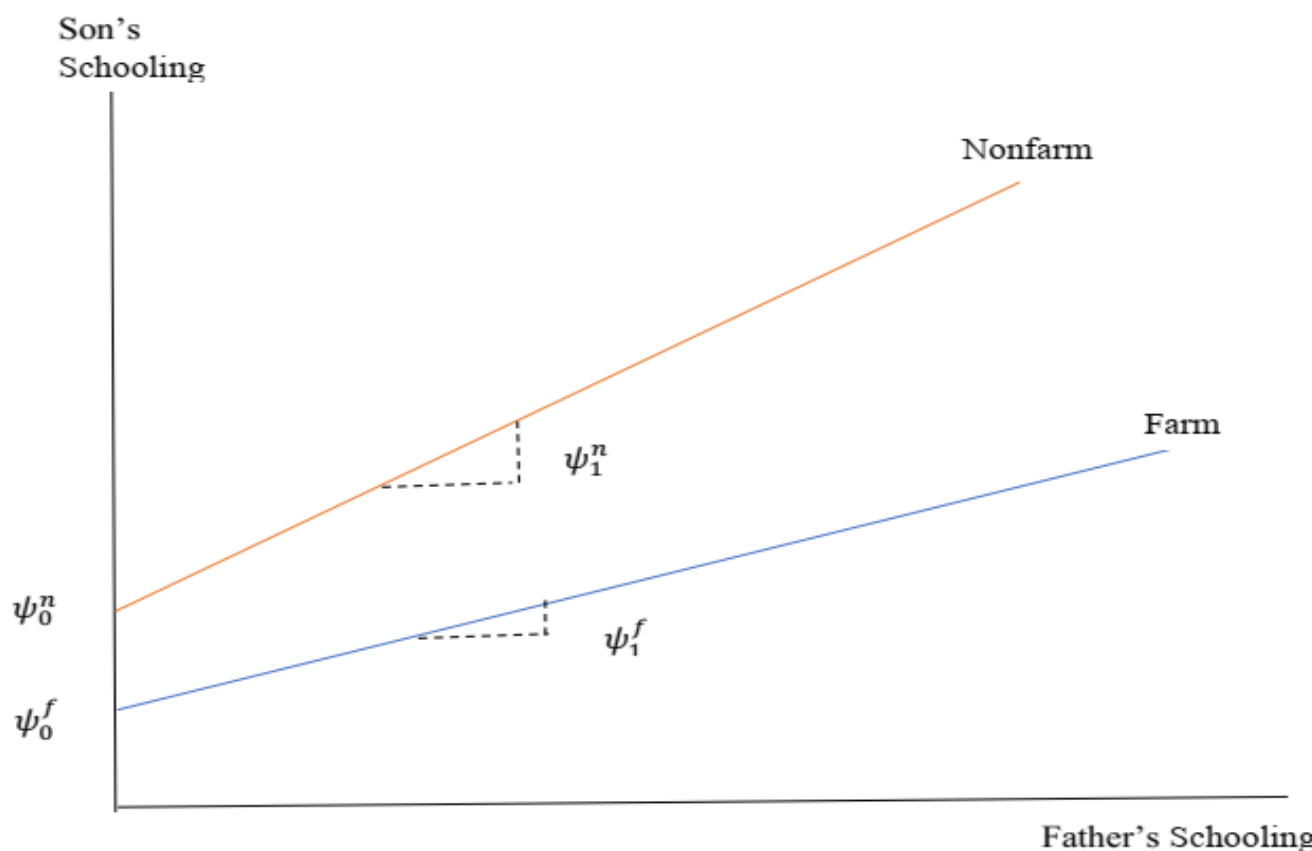

FIGURE 2

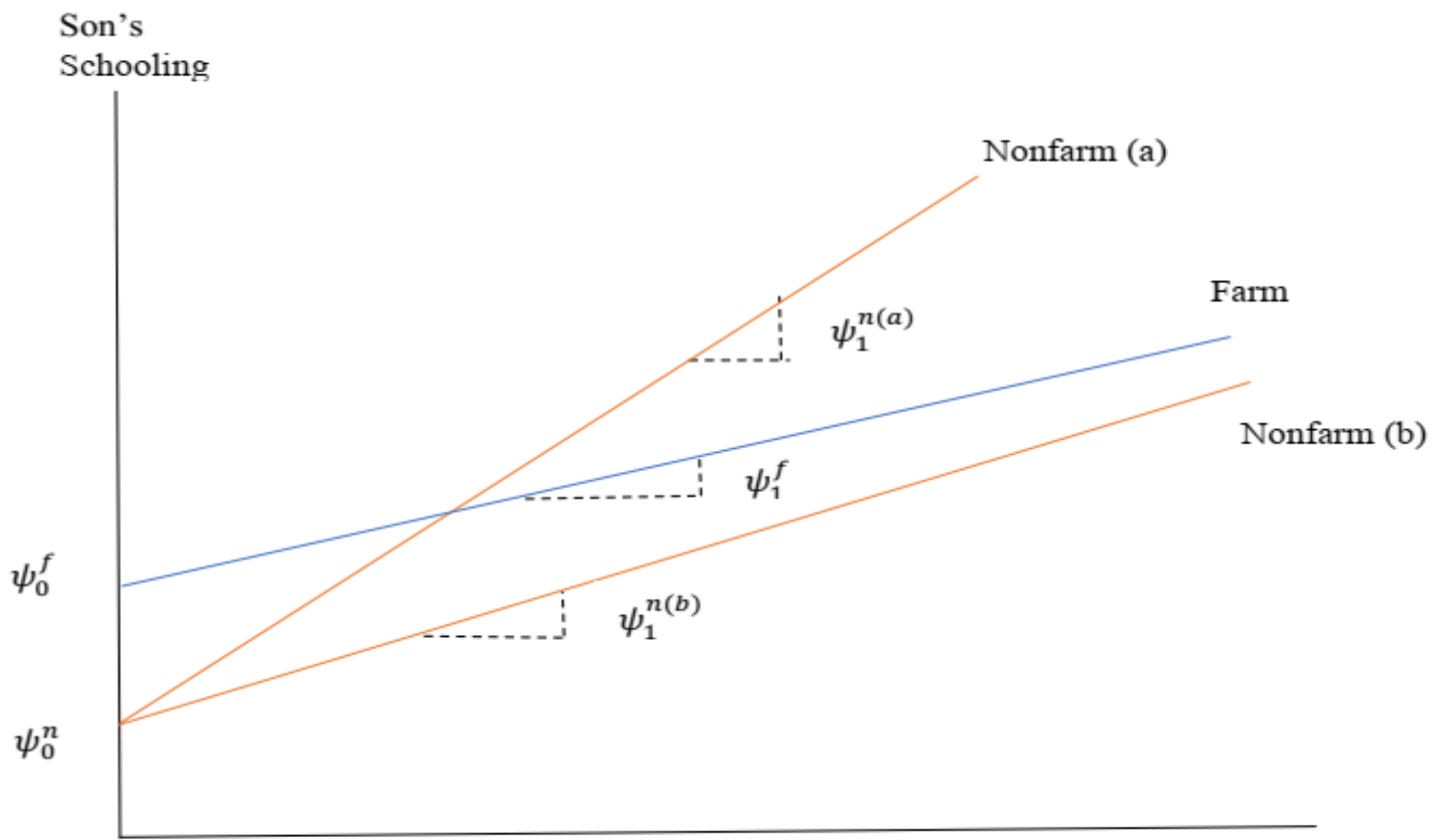

Father's Schooling 
Table 1: Relative Mobility and Test of Complementarity: Rural China and Rural India

\begin{tabular}{lcccc}
\hline & \multicolumn{2}{c}{ IGRC $\left(\boldsymbol{\psi}_{1}^{\boldsymbol{j}}\right)$} & \multicolumn{2}{c}{ IRC $\left(\boldsymbol{\delta}_{1}^{\boldsymbol{j}}\right)$} \\
\hline \multirow{3}{*}{ Combined Sample } & CHINA & INDIA & CHINA & INDIA \\
\cline { 2 - 5 } & $\mathbf{0 . 3 1 3}$ & $\mathbf{0 . 5 1 8}$ & $\mathbf{0 . 3 3 7}$ & $\mathbf{0 . 4 5 6}$ \\
& $(0.025)$ & $(0.020)$ & $(0.017)$ & $(0.014)$ \\
Farm & & & & \\
& $\mathbf{0 . 3 1 1}$ & $\mathbf{0 . 4 8 8}$ & $\mathbf{0 . 3 3 1}$ & $\mathbf{0 . 4 2 2}$ \\
\multirow{2}{*}{ Nonfarm } & $(0.033)$ & $(0.027)$ & $(0.032)$ & $(0.024)$ \\
& & & & \\
& $\mathbf{0 . 3 1 6}$ & $\mathbf{0 . 5 5 5}$ & $\mathbf{0 . 3 4 4}$ & $\mathbf{0 . 5 0 0}$ \\
& $(0.029)$ & $(0.027)$ & $(0.031)$ & $(0.024)$
\end{tabular}

Test of Complementarity (Farm/Nonfarm)

$\mathrm{H}_{0}$ : Farm and Nonfarm Coefficients are Equal

\begin{tabular}{lcccc}
\hline & \multicolumn{2}{c}{$\operatorname{IGRC}\left(\psi_{1}^{n}=\psi_{1}^{f}\right)$} & \multicolumn{2}{c}{$\operatorname{IRC}\left(\delta_{1}^{n}=\delta_{1}^{f}\right)$} \\
\hline \multirow{2}{*}{ F Statistic } & CHINA & INDIA & CHINA & INDIA \\
\cline { 2 - 5 } P-Value & 0.014 & 3.803 & 0.134 & 6.421 \\
& 0.906 & 0.052 & 0.715 & 0.012 \\
\hline
\end{tabular}

Notes: (1) IGRC stands for Intergenerational Regression Coefficient, and IRC stands for Intergenerational Rank Correlation. (2) The numbers in parenthesis are robust standard errors clustered at the Primary Sampling Unit level. (3) The number of observations for China: Combined (3305), Farm (1662), Nonfarm (1643), and for India: Combined (6952), Farm (4035), Nonfarm (2917). 
Table 2: Estimates of Intercepts and Test of Equality

\begin{tabular}{|c|c|c|c|c|}
\hline & \multicolumn{2}{|c|}{ IGRC Intercept $\left(\psi_{0}^{j}\right)$} & \multicolumn{2}{|c|}{ IRC Intercept $\left(\delta_{0}^{j}\right)$} \\
\hline & CHINA & INDIA & CHINA & INDIA \\
\hline Combined Sample & $\begin{array}{c}\mathbf{5 . 8 6 2} \\
(0.221)\end{array}$ & $\begin{array}{c}\mathbf{5 . 3 3 9} \\
(0.165)\end{array}$ & $\begin{array}{c}\mathbf{0 . 3 8 1} \\
(0.010)\end{array}$ & $\begin{array}{c}\mathbf{0 . 3 4 0} \\
(0.009)\end{array}$ \\
\hline Farm & $\begin{array}{c}\mathbf{5 . 7 1 3} \\
(0.282)\end{array}$ & $\begin{array}{c}\mathbf{5 . 6 1 2} \\
(0.219)\end{array}$ & $\begin{array}{c}\mathbf{0 . 3 7 1} \\
(0.025)\end{array}$ & $\begin{array}{c}\mathbf{0 . 3 6 4} \\
(0.017)\end{array}$ \\
\hline \multirow[t]{2}{*}{ Nonfarm } & $\begin{array}{c}\mathbf{6 . 0 1 2} \\
(0.237)\end{array}$ & $\begin{array}{c}\mathbf{4 . 9 8 0} \\
(0.193)\end{array}$ & $\begin{array}{c}\mathbf{0 . 3 9 1} \\
(0.022)\end{array}$ & $\begin{array}{c}\mathbf{0 . 3 0 7} \\
(0.015)\end{array}$ \\
\hline & \multicolumn{4}{|c|}{ Test of Equality (Farm/Nonfarm) } \\
\hline \multicolumn{5}{|c|}{ Ho: Farm and Nonfarm Intercepts are Equal } \\
\hline & \multicolumn{2}{|c|}{$\begin{array}{c}\text { IGRC Intercepts } \\
\left(\psi_{0}^{n}=\psi_{0}^{f}\right)\end{array}$} & \multicolumn{2}{|c|}{$\begin{array}{c}\text { IRC Intercepts } \\
\left(\delta_{0}^{n}=\delta_{0}^{f}\right)\end{array}$} \\
\hline & CHINA & INDIA & CHINA & INDIA \\
\hline F Statistic & 1.181 & 6.233 & 0.626 & 7.784 \\
\hline P-Value & 0.279 & 0.013 & 0.430 & 0.006 \\
\hline
\end{tabular}

Notes: (1) The numbers in bold in the upper panel are estimates of the intercepts from intergenerational persistence regression using years of schooling (Called IGRC intercepts), and from rank-rank regressions (called IRC intercepts). (2) the numbers in parenthesis are robust standard errors clustered at the Primary Sampling Unit level. 
Table 3: AET (2005) Sensitivity Analysis for Ability Bias

The Effects of Father's Higher Education on the Probability of Higher Education of Sons.

\begin{tabular}{ccccc}
\hline & \multicolumn{2}{c}{ CHINA } & \multicolumn{2}{c}{ INDIA } \\
\cline { 2 - 5 } & Farm & Nonfarm & Farm & Nonfarm \\
\hline \multirow{3}{*}{$=\mathbf{0}$} & $\mathbf{1 . 7 2}$ & $\mathbf{2 . 8 3}$ & $\mathbf{8 . 6 8}$ & $\mathbf{9 . 9 9}$ \\
& $(0.38)$ & $(0.46)$ & $(0.44)$ & $(0.45)$ \\
$\boldsymbol{\rho}=\mathbf{0 . 1 0}$ & $\mathbf{1 . 1 7}$ & $\mathbf{2 . 1 4}$ & $\mathbf{7 . 6 4}$ & $\mathbf{9 . 4 6}$ \\
& $(0.44)$ & $(0.51)$ & $(0.47)$ & $(0.48)$ \\
$\boldsymbol{\rho}=\mathbf{0 . 2 0}$ & $\mathbf{0 . 3 8}$ & $\mathbf{1 . 2}$ & $\mathbf{6 . 2 7}$ & $\mathbf{8 . 6 5}$ \\
& $(0.50)$ & $(0.57)$ & $(0.51)$ & $(0.53)$ \\
$\boldsymbol{\rho}=\mathbf{0 . 3 0}$ & $\mathbf{- 0 . 6 6}$ & $\mathbf{- 0 . 0 2}$ & $\mathbf{4 . 5 3}$ & $\mathbf{7 . 4 8}$ \\
& $(0.57)$ & $(0.63)$ & $(0.55)$ & $(0.58)$ \\
$\boldsymbol{\rho}=\mathbf{0 . 4 0}$ & $\mathbf{- 1 . 9 9}$ & $\mathbf{- 1 . 5 2}$ & $\mathbf{2 . 3 9}$ & $\mathbf{5 . 8 8}$ \\
& $(0.64)$ & $(0.68)$ & $(0.58)$ & $(0.63)$ \\
& & & & \\
\hline
\end{tabular}

Notes: (1) AET (2005) stands for Altonji, Elder and Taber (2005, Journal of Political Economy) Biprobit sensitivity analysis. (2) $\boldsymbol{\rho}$ stands for correlation in cognitive ability of father and son. Estimates in the first row are the univariate Probit estimates. The upper bound $\boldsymbol{\rho}=\mathbf{0 . 4 0}$ is based on economics and behavioral genetics literature. (3) The numbers in bold are percentage points increase in the probability of higher education of sons when the father has higher education. (3) Higher education for parents implies more than primary, and for sons in India more than 10 years of schooling, for sons in China more than 9 years of schooling. (4) The numbers in parenthesis are standard errors clustered at the PSU level. 


\begin{tabular}{|c|c|c|c|c|}
\hline \multirow{2}{*}{\multicolumn{5}{|c|}{$\begin{array}{c}\text { Table 4: Father's Education and Household Income } \\
\text { Panel A: Estimates for Rural China }\end{array}$}} \\
\hline & & & & \\
\hline & \multicolumn{2}{|c|}{ Intercept } & \multicolumn{2}{|c|}{ Slope (Returns to Education) } \\
\hline & Farm & Nonfarm & Farm & Nonfarm \\
\hline \multirow[t]{2}{*}{ CHIP 2002} & 8344.64 & 8582.80 & 275.32 & 335.42 \\
\hline & $(670.34)$ & $(832.97)$ & $(91.38)$ & $(108.72)$ \\
\hline \multirow[t]{2}{*}{ CHIP 1995} & 4608.86 & 4457.28 & 34.21 & 107.45 \\
\hline & $(666.28)$ & $(383.14)$ & $(71.14)$ & $(43.19)$ \\
\hline
\end{tabular}

Test of Equality Between Farm and Nonfarm

CHIP 2002

$\mathrm{H}_{0}$ : Intercepts are Equal

$\mathrm{H}_{0}$ : Slopes are Equal

F Statistic

0.08

0.30

P-value

0.78

0.58

CHIP 1995

F Statistic

0.06

0.96

P-value

0.81

0.33

\begin{tabular}{|c|c|c|c|c|}
\hline & \multicolumn{3}{|c|}{ Panel B: Estimates for Rural India } & \\
\hline & \multicolumn{2}{|c|}{ Intercept } & \multicolumn{2}{|c|}{ Slope (Returns to Education) } \\
\hline & Farm & Nonfarm & Farm & Nonfarm \\
\hline NSS 1993 & $\begin{array}{c}1199.27 \\
(9.67)\end{array}$ & $\begin{array}{c}\mathbf{1 1 7 2 . 1 7} \\
(13.57)\end{array}$ & $\begin{array}{l}\mathbf{6 8 . 1 7} \\
(2.52)\end{array}$ & $\begin{array}{l}77.92 \\
(3.28)\end{array}$ \\
\hline
\end{tabular}

Test of Equality Between Farm and Nonfarm

$\mathrm{H}_{0}$ : Intercepts are Equal

$\mathrm{H}_{0}$ : Slopes are Equal

$\begin{array}{lll}\text { F Statistic } & 2.99 & 5.71 \\ \text { P-value } & 0.08 & 0.02\end{array}$

Notes: (1) The dependent variable for Rural China is the average household income (total). CHIP 2002 is the average of the last 5 years of total household income, and CHIP 1995 is the average of the last 3 years of household income. The dependent variable for India is total household expenditure. (2) The numbers in parenthesis are standard errors. (3) $\mathrm{H}_{0}$ stands for Null Hypothesis. (4) The number of observations for CHIP 1995: Farm (1709), Nonfarm (3893), and for CHIP 2002: Farm (4457), Nonfarm (4087). For NSS (1993), the number of observations are Nonfarm (20535), and Farm (48196). 
Table 5: Intergenerational Persistence in Education (18-28 Age Cohort, CFPS)

Panel A: Estimates Based on Years of Schooling

\begin{tabular}{cccccc}
\hline \multicolumn{2}{c}{ Intercept } & $\left(\boldsymbol{\psi}_{0}^{j}\right)$ & & \multicolumn{2}{c}{ IGRC $\left(\boldsymbol{\psi}_{1}^{j}\right)$} \\
\cline { 1 - 2 } \cline { 5 - 6 } \cline { 5 - 6 } Farm & Nonfarm & & Farm & Nonfarm \\
\cline { 1 - 2 }$(0.997$ & $\mathbf{7 . 1 7 3}$ & & $\mathbf{0 . 2 7 4}$ & $\mathbf{0 . 3 3 7}$ \\
$(0.341)$ & $(0.308)$ & & $(0.035)$ & $(0.032)$
\end{tabular}

Test of Equality Between Farm and Nonfarm

$\mathrm{H}_{0}$ : Intercepts are Equal

F Statistic

$$
\left(\psi_{0}^{n}=\psi_{0}^{f}\right)
$$

0.244

0.622

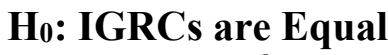
$\left(\psi_{1}^{n}=\psi_{1}^{f}\right)$

2.632

0.107

Panel B: Estimates Based on Schooling Ranks

\begin{tabular}{ccccc}
\multicolumn{2}{c}{ Intercept } & $\left(\boldsymbol{\delta}_{0}^{j}\right)$ & & \multicolumn{2}{c}{ IRC $\left(\boldsymbol{\delta}_{\mathbf{1}}^{\boldsymbol{j}}\right)$} \\
\cline { 1 - 2 } \cline { 5 - 6 } \cline { 5 - 6 } Farm & Nonfarm & & Farm & Nonfarm \\
\hline $\mathbf{0 . 3 9 9}$ & $\mathbf{0 . 4 0 4}$ & & $\mathbf{0 . 3 0 4}$ & $\mathbf{0 . 3 7 3}$ \\
$(0.027)$ & $(0.027)$ & & $(0.034)$ & $(0.035)$
\end{tabular}

Test of Equality Between Farm and Nonfarm

Ho: Intercepts are Equal

$\mathrm{H}_{0}$ : Slopes are Equal

$$
\left(\delta_{0}^{n}=\delta_{0}^{f}\right)
$$

F Statistic

0.028

$\left(\delta_{1}^{n}=\delta_{1}^{f}\right)$

P-Value

0.868

2.792

0.097 


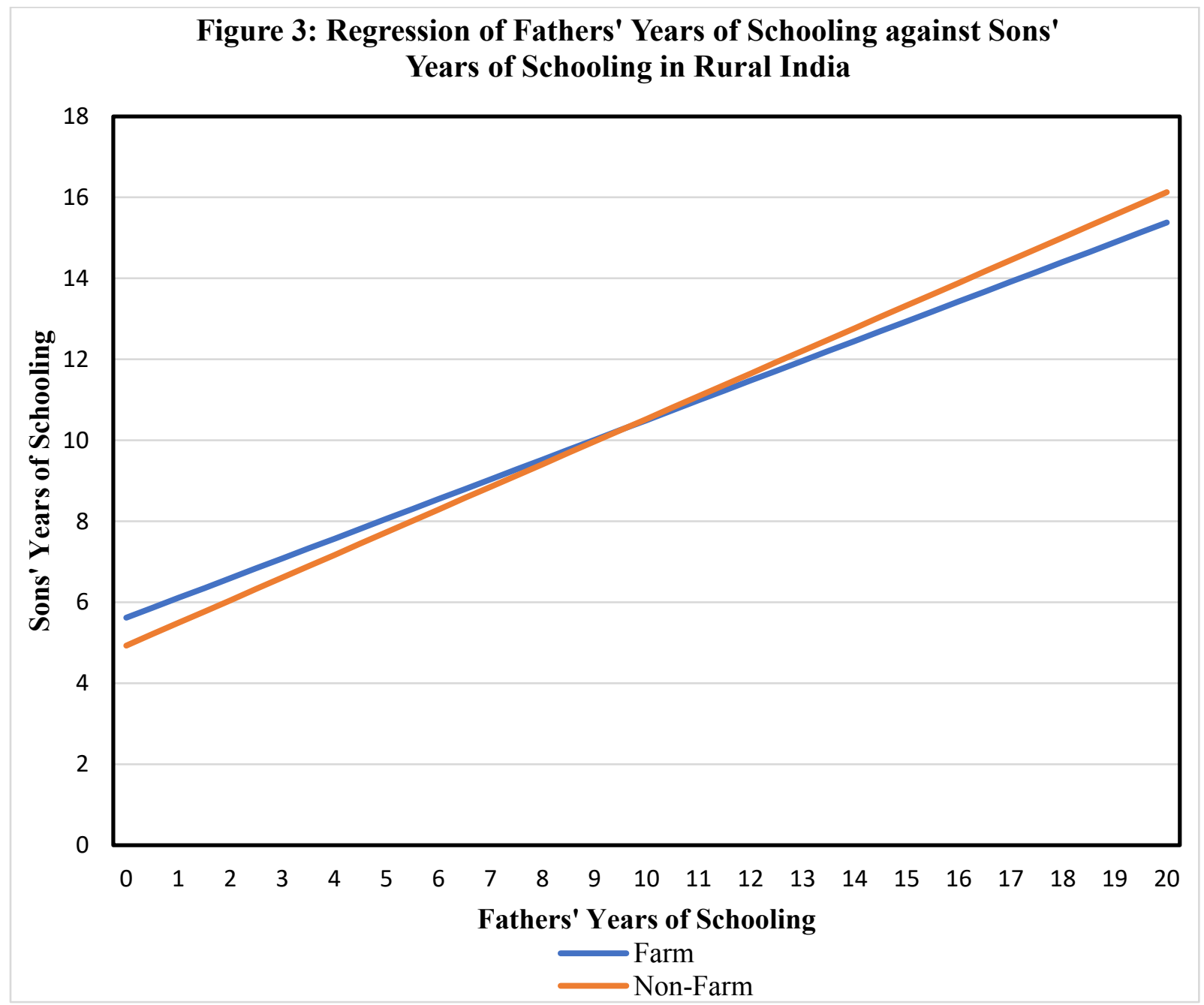


Figure 4: Regression of Fathers' Years of Schooling against Sons' Years of Schooling in Rural China

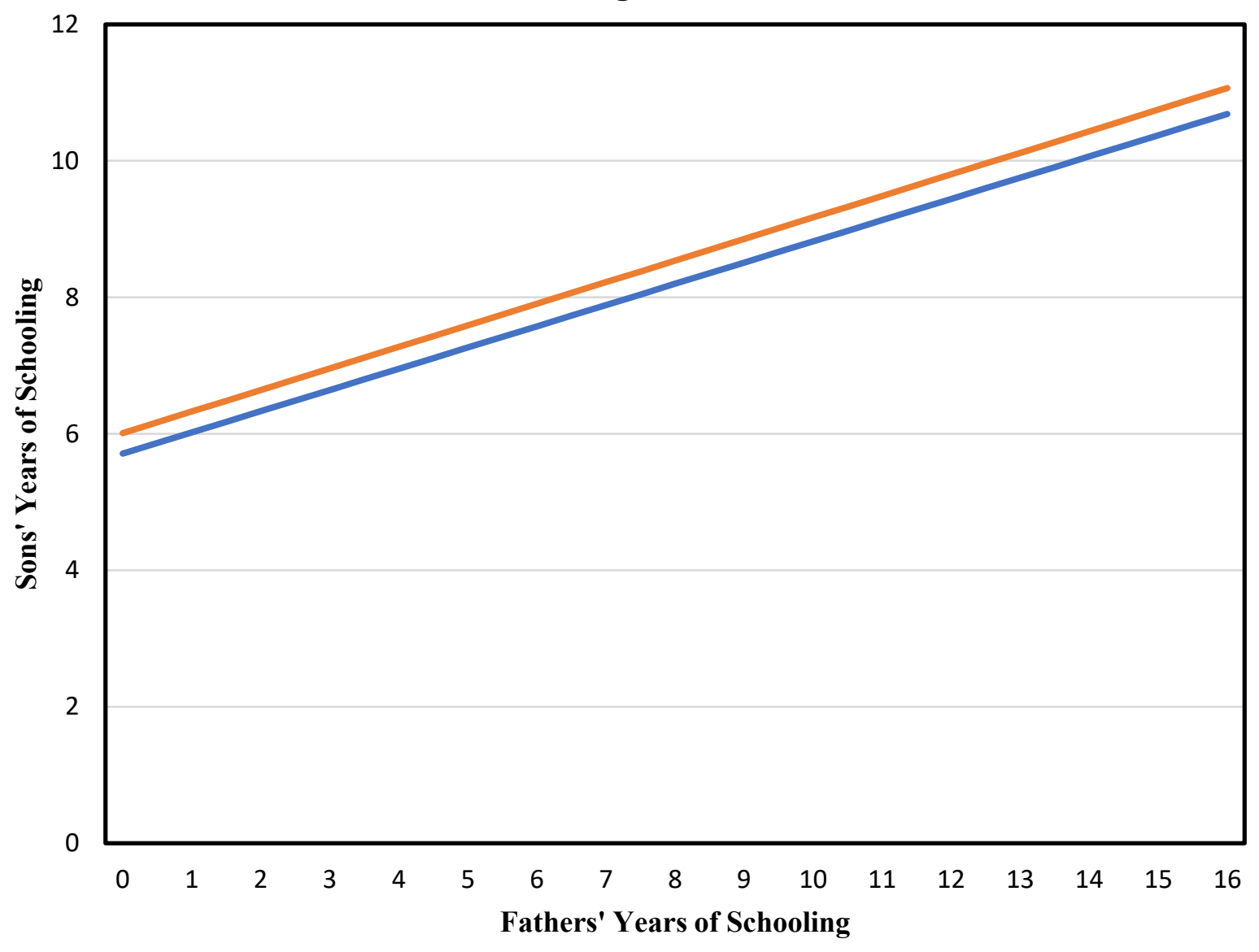

Farm Non-Farm 


\section{Online Appendix A: Coresidency and Truncation Bias in Rural China: CFPS 2010 vs. CHIP 2002}

An important advantage of the data used in this study is that the estimates are free of truncation bias that arises from using coresidency to define household membership in a survey. Emran, Greene, and Shilpi (2018) provide an in-depth discussion on the magnitude of truncation bias in the context of rural India. To the best of our knowledge, there are no studies on the effects of sample truncation due to coresidency in the context of rural China in the existing literature. To understand the extent of truncation bias in the context of rural China, we compare the estimates free of truncation in Tables 1 and 2 with the corresponding estimates using data from the Chinese Household Income Project (CHIP 2002). This may be of independent interest to many researchers as CHIP data sets have been widely used to study intergenerational mobility in China including by some of the authors of the current paper.

Using CHIP 2002 data, appendix Table A.2 reports estimates for two age ranges: (i) the same age cohorts as in Tables 1 and 2 in the main text of the paper (21-57 years old in 2002), ${ }^{43}$ and (ii) the full sample with 18-65 years old children in 2002. The estimates of IGRC from CHIP 2002 are about 25 percent lower on average compared to the CFPS 2010 estimates (taking the CHIP 2002 estimate as the base). The estimates of the intercepts are, in contrast, biased upward in CHIP 2002, about 15-18 percent higher than the corresponding estimate from the CFPS data. The evidence that the coresident sample causes substantial downward bias in the slope estimates, but upward bias in the intercept estimates from the CHIP 2002 data is consistent with the evidence from India and Bangladesh provided by Emran, Greene and Shilpi (2018), and Emran and Shilpi (2018). The substantive conclusions are also less robust; the test of separability shows different results for IGRC and IRC for the age cohorts overlapping with the main estimation samples from the CFPS used in Tables 1 and 2. While the null hypothesis of separability cannot be rejected for IGRC estimates at the 10 percent level, the IRC estimates reject separability at the 5 percent level. An analysis based on the coresident sample thus can lead to wrong conclusions about the interaction between parent's education and occupation. ${ }^{44}$

\footnotetext{
${ }^{43}$ This ensures that the age cohorts in CHIP 2002 overlap with the 29-65 age cohorts used for CFPS 2010 data.

${ }^{44} \mathrm{~A}$ full analysis of CHIP 2002 data is presented in an unpublished work by Emran and Sun (2015b). As noted in the main text, the evidence and conclusions in this paper supersede those in Emran and Sun (2015b).
} 


\section{Online Appendix B: An Approach to Nature vs. Nurture}

The approach developed here exploits the restrictions implied by the recent estimates of intergenerational correlation in cognitive ability in economics in a triangular biprobit model a' la Altonji et al. (2005), and performs sensitivity analysis over a narrow interval of the correlation parameter. This approach requires binary classification of educational attainment. We define a dummy $D_{i}^{p}$ that takes on the value 1 when the father of a child has more than primary schooling and zero otherwise. Analogously we define a binary variable for children's education $D_{i}^{c}$ which takes on the value of 1 when a child's schooling years is higher than a threshold (junior high schooling for China and secondary schooling for India). This means that we have a $[2 \times 2]$ occupation and education set-up. Consider the following triangular model of children's and parent's education:

$$
\begin{gathered}
\operatorname{Pr}\left(D_{i}^{c}=1\right)=\Phi\left(\lambda_{0}^{j}+\lambda_{1}^{j} D_{i}^{p}+X_{i}^{\prime} \Pi^{j}+\varsigma_{i}\right) \\
\operatorname{Pr}\left(D_{i}^{p}=1\right)=\Phi\left(\gamma_{0}^{j}+X_{i}^{\prime} \Gamma^{j}+\epsilon_{i}\right)
\end{gathered}
$$

where $\Phi$ is the normal CDF and superscript $j$ refers to parental occupation, i.e., $j \in\{f, n\}$. The error terms capture the unobserved factors including ability, part of which is genetically transmitted from father to son in our application.

The choice of the educational cut-offs described above is based on the following considerations. For parental generation, the cut-off is primary schooling, which equals 5 years of schooling in India and 6 years in China. For children in India, the cut-off we chose is 10 years of schooling that correspond to the completion of secondary schooling. The 10th year is a natural focal point for India as the students take one of the most important public examinations at the end of 10th grade. For China the cut-off used is junior high schooling which corresponds to 9 years of schooling. The 9 th year cut-off is a focal point in China because of the 9-year compulsory schooling policy adopted by the government in 1986. While a lump in the distribution of children's schooling attainment at the 9th year of schooling may be driven by government policy, whether a child goes beyond 9 years of schooling would reflect more faithfully the effects of family background. Thus we define all the dummies as strict inequalities; for example, for rural China, we set $D^{c}=1$ when a child attains higher than 9 years of schooling and zero otherwise. The conclusions below, however, do not depend on the precise cut-off chosen for the educational attainment dummies. ${ }^{45}$

\footnotetext{
${ }^{45}$ As part of robustness checks, we estimated biprobit models for China using 5 years cut-off for father
} 
It is useful to decompose the error terms in the triangular model into two parts, one genetically transmitted (denoted as $\phi_{i}$ ) and the other orthogonal to the genetic component:

$$
\begin{aligned}
\varsigma_{i} & =\phi_{i}^{c}+\tilde{\varsigma}_{i} \\
\epsilon_{i} & =\phi_{i}^{p}+\tilde{\epsilon}_{i}
\end{aligned}
$$

So $\operatorname{Cov}\left(\varsigma_{i}, \epsilon_{i}\right)=\operatorname{Cov}\left(\phi_{i}^{c}, \phi_{i}^{p}\right)+\operatorname{Cov}\left(\tilde{\varsigma}_{i}, \tilde{\epsilon}_{i}\right)$. The focus is on the role played by the genetic component represented by $\operatorname{Cov}\left(\phi_{i}^{c}, \phi_{i}^{p}\right)$.

We take advantage of a substantial literature in economics and behavioral genetics that provides estimates of correlation between parents and children in cognitive ability. According to the estimates reported by Black et al. (2009) and Björklund et al. (2010), $\operatorname{Cov}\left(\phi_{i}^{c}, \phi_{i}^{p}\right) \in[0.35,0.38]$. A meta-analysis of behavioral genetic studies by Plomin and Spinath (2004) reports a correlation of 0.40 .

Let $\rho=\operatorname{Corr}\left(\varsigma_{i}, \epsilon_{i}\right)$. We estimate the bivariate probit model above by imposing $\rho=$ $0.10,0.20,0.30,0.40 .{ }^{46}$ Thus we allow for different degrees of correlation in the error terms of the triangular model driven by genetic transmissions across generations. It is important to appreciate that the estimates of intergenerational schooling persistence from the sensitivity analysis with $\rho=0.40$ can be interpreted as the lower bounds on the true intergenerational effects due to economic and social factors. The estimates of ability correlations in the literature discussed above are likely to be biased upward as measures of genetic correlations at birth because they partly capture the dynamic interactions between family environment and genetics up to the age when the ability measurements are taken. ${ }^{47}$ For example, the careful recent analysis by Gronqvist et al. (2017) uses measures of cognitive ability taken at age 13 .

The results from the biprobit sensitivity analysis are reported in Table 3 of the main text and discussed at the beginning of section (6). We report the marginal effects of and 10 years cut-off for children, so that the educational attainment dummies in China match exactly those in India in terms of years of schooling. The estimates are very close to those reported in Table 3 of the main text. The details are available from the authors.

${ }^{46}$ In an interesting recent paper, Gronqvist et al. (2017) show that the estimates of ability correlation may be biased downward because of measurement error, and they report estimates in the range of 0.42-0.48. However, note that the educational attainment as measured by years of schooling is also usually measured with error. It thus seems reasonable to use 0.40 as the upper bound for our analysis, assuming that the measurement errors in schooling and cognitive ability largely offset each other.

${ }^{47}$ This includes the in-utero effects on a child's health which is found to be of substantial magnitude according to a large literature. Please see the survey by Almond and Currie (2011). Recent evidence shows that socioeconomic status a child born into affects the development of brain in a significant way (Noble et al. $(2015))$. 
switching the parental educational dummy from zero (primary or below) to one (more than primary) which implies that the estimates of intergenerational persistence depend on all of the probit coefficients in the model, including the intercept term. ${ }^{48}$ The main text of the paper provides a concise discussion of the main results from this analysis. Here we provide a more detailed discussion.

\section{Effects of Positive Ability Correlations in Rural India}

The estimates from the univariate probit model for India reported in row 1 of Table 3 of the main text shows that the pattern of the effects is broadly similar to that found in the estimates based on years of schooling in Table 1 and Table 2 in the main text. The sons born to fathers with more than primary schooling enjoy a higher probability of attaining more than secondary schooling, and this effect is larger for the children with fathers in nonfarm occupation.

More important and interesting for our purpose is how the estimates are affected when we relax the assumption of $\rho=0$ imposed in the univariate probit estimates. Consistent with a priori expectation, the magnitude of the estimated effects declines monotonically with higher values of intergenerational ability correlation $\rho$. However, the estimated effect of having a better educated father remains positive and statistically significant at the 1 percent level across the board even when we set the value of $\rho$ at its upper bound of 0.40 . This can be interpreted as strong evidence that the estimated effects in India are not likely to be driven exclusively by mechanical effects of genetic transmission of ability.

\section{Effects of Positive Ability Correlations in Rural China}

The estimates of father's effect in rural China for alternative values of genetic correlation in ability are reported in the first two columns of Table 3 in the main text. The estimates from the univariate probit model under the assumption that $\rho=0$ show that the effects for both farm and nonfarm households in China are much smaller in magnitude when compared to the corresponding estimates for India. This confirms the conclusion based on years of schooling as a measure of educational attainment that the sons in rural China enjoy much higher educational mobility compared to the sons in rural India. More important is the evidence that the estimated effects become very small in China when we set $\rho=0.20$. The advantage due to the higher educated father declines effectively to zero when we set $\rho=0.30$, as the estimated effects turn negative for both the farm and nonfarm households.

\footnotetext{
${ }^{48}$ The AET sensitivity analysis including the quadratic age controls yield similar conclusions to those based on Table 3 in the main text. The results are available from the authors upon request.
} 
The evidence thus suggests that the estimates of intergenerational persistence in China reported in Table 1 and Table 2 in the main text could be entirely driven by genetic correlations in ability. This suggests high intergenerational educational mobility during the decades of 1980s and 1990s in rural China, for the sons of both the farmer and nonfarmer fathers. However, as discussed in details in the main text (see sections (6.1) and (6.2)), the evidence that the observed persistence in rural China could be explained away by genetic correlation in cognitive ability does not necessarily imply that economic forces did not play a role in determining the pattern across farm and nonfarm households. 


\section{APPENDIX TABLES}

Table A.1: Summary Statistics (Main Overlapping Samples)

\begin{tabular}{|c|c|c|c|c|}
\hline & Mean & SD & Min & Max \\
\hline & \multicolumn{4}{|c|}{ CFPS 2010} \\
\hline Son's Schooling (years) & 6.31 & 4.14 & $\mathbf{0}$ & 19 \\
\hline Father's Schooling (years) & 3.81 & 4.14 & $\mathbf{0}$ & 16 \\
\hline Father in Agriculture (dummy) & 0.48 & 0.50 & $\mathbf{0}$ & 1 \\
\hline Son's Age (years) & 39.78 & 7.69 & 29 & 65 \\
\hline \multirow[t]{2}{*}{ Father's Age (years) } & 67.92 & 8.83 & 45 & 96 \\
\hline & \multicolumn{4}{|c|}{ REDS 1999} \\
\hline Son's Schooling (years) & 6.26 & 5.14 & $\mathbf{0}$ & 21 \\
\hline Father's Schooling (years) & 4.13 & 4.41 & $\mathbf{0}$ & 20 \\
\hline Father in Agriculture (dummy) & 0.59 & 0.49 & $\mathbf{0}$ & 1 \\
\hline Son's Age (years) & 28.65 & 7.88 & 18 & 54 \\
\hline Father's Age (years) & 59.67 & 9.86 & 34 & 98 \\
\hline
\end{tabular}

NOTES: (1) CFPS stands for China Family Panel Studies and REDS stand for Rural Economic and Demographic Survey. (2) SD stands for standard deviation. (3) No. of observations for CFPS is 3305, and for REDS 6887. 
Table A.2: Estimates of Intergenerational Educational Persistence in Rural China from CHIP 2002

\begin{tabular}{|c|c|c|c|c|}
\hline & Panel A: Children & 18-65 Years & \multirow{2}{*}{\multicolumn{2}{|c|}{ INTERCEPT }} \\
\hline & \multicolumn{2}{|c|}{ SLOPE } & & \\
\hline & $\operatorname{IGRC}\left(\psi_{1}^{j}\right)$ & $\operatorname{IRC}\left(\delta_{1}^{j}\right)$ & $\left(\boldsymbol{\psi}_{0}^{j}\right)$ & $\left(\delta_{0}^{j}\right)$ \\
\hline \multirow[t]{2}{*}{ Combined } & 0.265 & 0.295 & 7.105 & 0.357 \\
\hline & $(0.018)$ & $(0.019)$ & $(0.163)$ & $(0.016)$ \\
\hline \multirow[t]{2}{*}{ Farm } & 0.245 & 0.263 & 7.075 & 0.353 \\
\hline & $(0.025)$ & $(0.026)$ & $(0.202)$ & $(0.019)$ \\
\hline \multirow[t]{3}{*}{ Non-farm } & 0.266 & 0.305 & 7.29 & 0.376 \\
\hline & $(0.024)$ & $(0.027)$ & $(0.219)$ & $(0.022)$ \\
\hline & \multicolumn{2}{|l|}{ Test of Separability } & \multicolumn{2}{|c|}{ Test of Equality } \\
\hline & $\left(\psi_{1}^{n}=\psi_{1}^{f}\right)$ & $\left(\delta_{1}^{n}=\delta_{1}^{f}\right)$ & $\left(\psi_{0}^{n}=\psi_{0}^{f}\right)$ & $\left(\delta_{0}^{n}=\delta_{0}^{f}\right)$ \\
\hline F-statistics & 0.410 & 1.375 & 0.700 & 0.917 \\
\hline P-value & 0.521 & 0.243 & 0.403 & 0.340 \\
\hline
\end{tabular}

Panel B: Children of 21-57 years age in 2002

\begin{tabular}{|c|c|c|c|c|}
\hline \multirow[b]{3}{*}{ Combined } & \multicolumn{2}{|c|}{ SLOPE } & \multicolumn{2}{|c|}{ INTERCEPT } \\
\hline & IGRC $\left(\psi_{1}^{j}\right)$ & $\operatorname{IRC}\left(\delta_{1}^{j}\right)$ & $\left(\boldsymbol{\psi}_{0}^{j}\right)$ & $\left(\delta_{0}^{j}\right)$ \\
\hline & 0.262 & 0.283 & 7.074 & 0.360 \\
\hline & $(0.019)$ & $(0.021)$ & $(0.174)$ & $(0.017)$ \\
\hline \multirow[t]{2}{*}{ Farm } & 0.226 & 0.237 & 7.127 & 0.361 \\
\hline & $(0.027)$ & $(0.027)$ & $(0.216)$ & $(0.021)$ \\
\hline \multirow[t]{3}{*}{ Non-farm } & 0.277 & 0.310 & 7.180 & 0.372 \\
\hline & $(0.026)$ & $(0.028)$ & $(0.234)$ & $(0.023)$ \\
\hline & \multicolumn{2}{|l|}{ Test of Separability } & \multicolumn{2}{|c|}{ Test of Equality } \\
\hline & $\left(\psi_{1}^{n}=\psi_{1}^{f}\right)$ & & $\left(\psi_{0}^{n}=\psi_{0}^{f}\right)$ & \\
\hline F-statistics & 2.216 & 4.205 & 0.039 & 0.189 \\
\hline P-value & 0.139 & 0.043 & 0.844 & 0.664 \\
\hline
\end{tabular}


Table A.3: Evidence on Complementarity and Intercept Differences with Quadratic Age Controls (Years of Schooling)

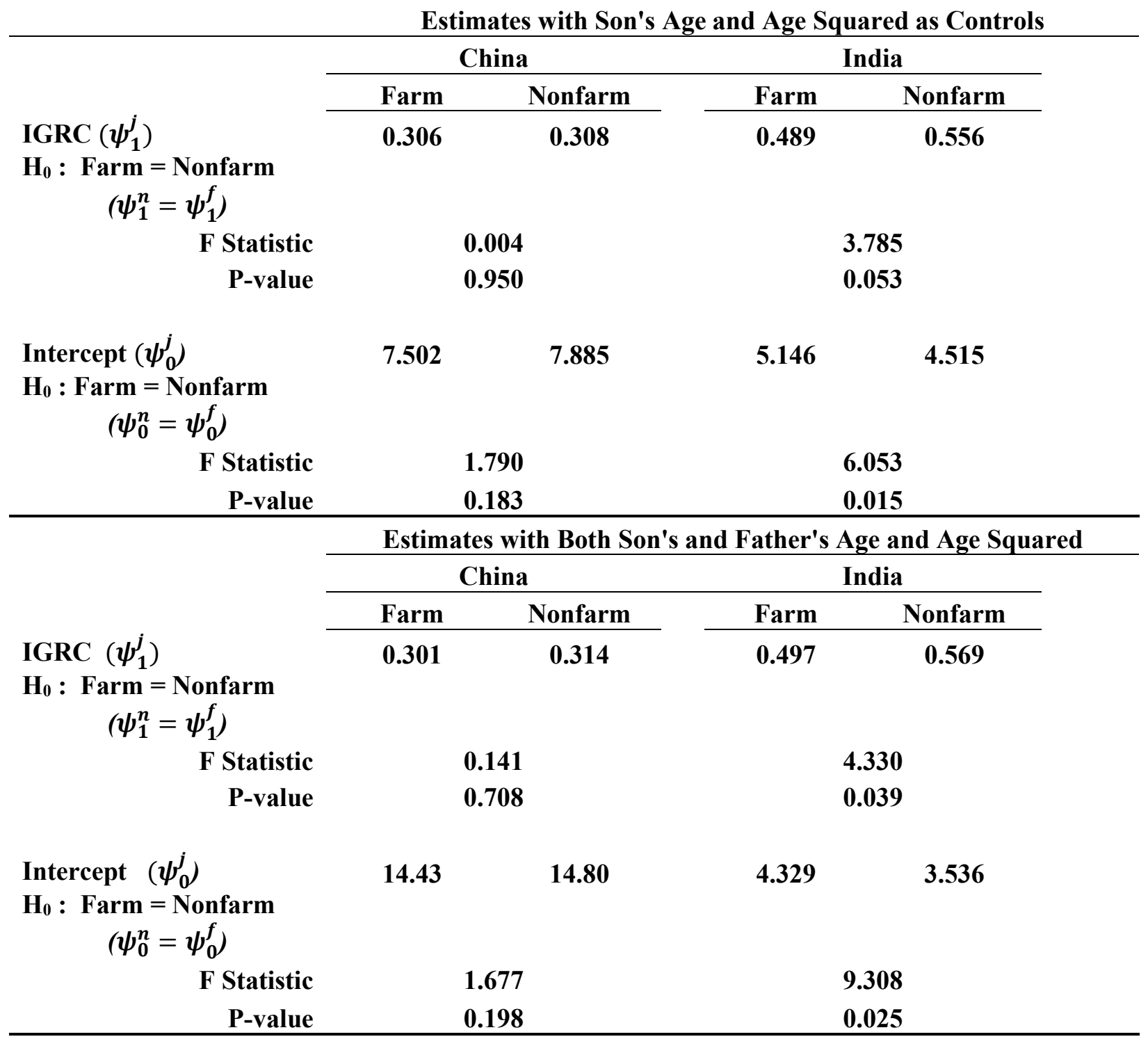


Table A.4: Evidence on Complementarity and Intercept Differences with Quadratic Age Controls (Schooling Rank)

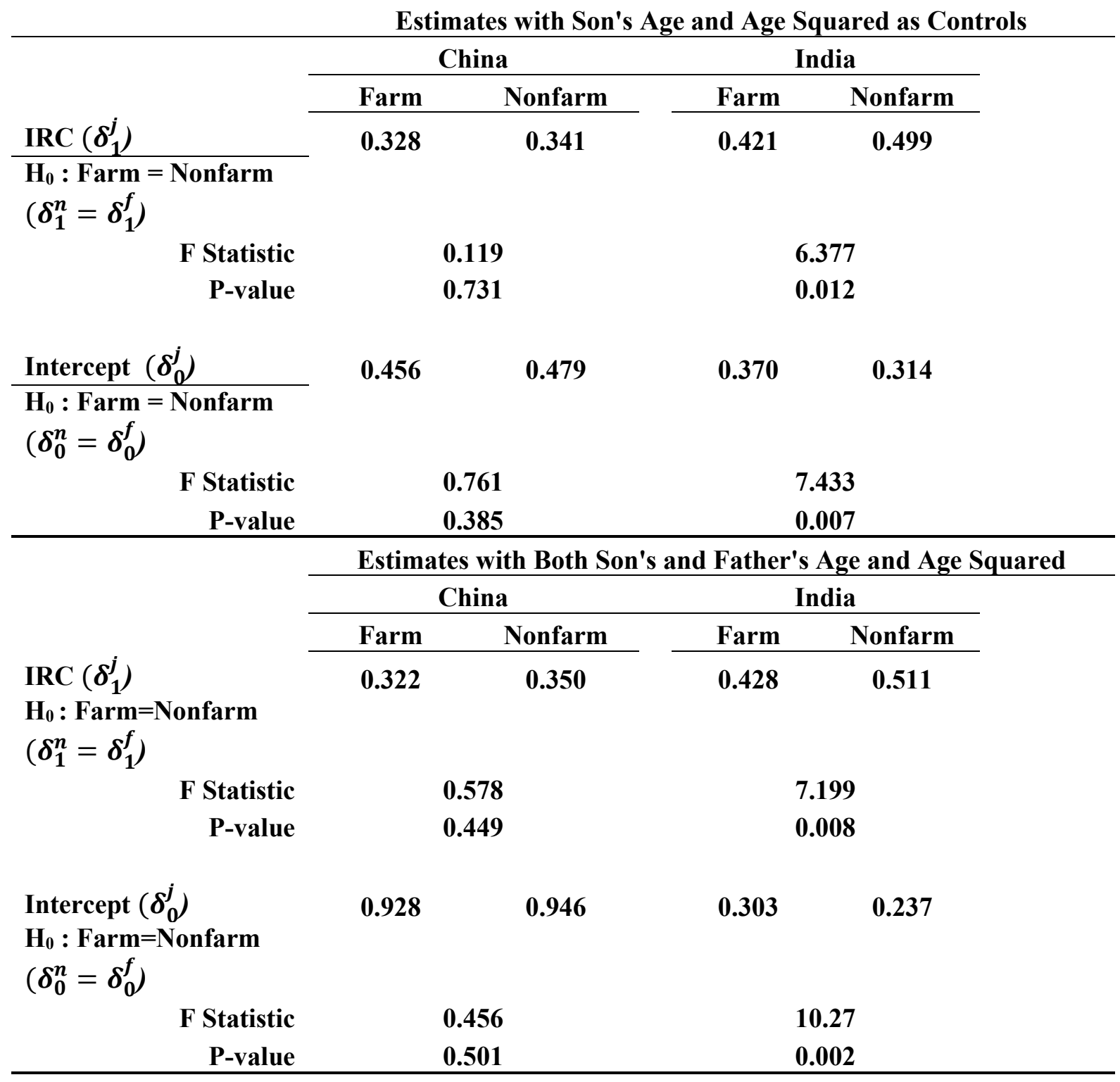




\begin{tabular}{lccccc}
\hline & \multicolumn{1}{c}{ Table A.5: Father's Education and Household Income } \\
(Control for Number of Children)
\end{tabular}

Test of Equality Between Farm and Nonfarm

$\mathrm{H}_{0}$ : Intercepts are Equal

$\mathrm{H}_{0}$ : Slopes are Equal

$\begin{array}{lcc}\text { F Statistic } & 591.19 & 9.98 \\ \text { P-value } & 0.000 & 0.002\end{array}$

Notes: (1) The dependent variable for Rural China is the average household income (total). CHIP 2002 is the average of the last 5 years of total household income, and CHIP 1995 is the average of the last 3 years of household income. The dependent variable for India is total household expenditure. (2) The numbers in parenthesis are standard errors. (3) $\mathrm{H}_{0}$ stands for Null Hypothesis. (4) The number of observations for CHIP 1995: Farm (1709), Nonfarm (3893), and for CHIP 2002: Farm (4457), Nonfarm (4087). For NSS (1993), the number of observations is Nonfarm (20535), and Farm (48196). 